\title{
ARTICLE
}

Cite this: DOI: $10.1039 /$ xoxxooooox

Received ooth January 2012, Accepted ooth January 2012

DOI: $10.1039 / \times 0 x \times 00000 x$

www.rsc.org/

\section{Hydrogen- and halogen-bond cooperativity in determining the crystal packing of dihalogen Charge- Transfer adducts: a study case from heterocyclic pentatomic chalcogenone donors ${ }^{\dagger}$}

\author{
Riccardo Montis, ${ }^{\text {a, }}$ Massimiliano Arca, ${ }^{\text {a }}$ M. Carla Aragoni, ${ }^{\text {a }}$ Antonio Bauzá, ${ }^{\text {b }}$ Francesco \\ Demartin, ${ }^{\mathrm{c}}$ Antonio Frontera, ${ }^{\mathrm{b}, *}$ Francesco Isaia, ${ }^{\mathrm{a}}$ Vito Lippolis ${ }^{\mathrm{a}, *}$
}

\begin{abstract}
Three new molecular CT adducts with dihalogens, based on 5,5-dimethyl-2-thiohydantoin (dth) and 1,5, 5-trimethyl-2-thiohydantoin (mdth) donor molecules have been synthesised and characterised by single crystal X-ray diffraction and their crystal structures compared with those of previously published analogous compounds to assess the role of molecular shape of the donors, and cooperativity and competition between hydrogen-bonds (HBs) and halogen-bonds (XBs) in defining the observed supramolecular architectures at the solid state.The study of the role played by these factors was supported by several computational tools. The structural features at the base of the crystal packings observed is the formation of dimers of donor molecules via complementary $\mathrm{N}-\mathrm{H} \cdots \mathrm{O}$ or $\mathrm{N}-\mathrm{H} \cdots \mathrm{S}$ HBs. These dimers are arranged in space in 2D architectures via further interactions involving the S/Se $\cdots I-$ $\mathrm{I} / \mathrm{Br} \mathrm{XBs}$. Interestingly, in most of the cases the XB interactions strengthens upon formation of the selfassembled H-bonded dimers, indicating a favourable cooperativity effect which is at the base of the supramolecular architectures formed.
\end{abstract}

\section{Introduction}

Among the different non-covalent forces involved in the formation of crystalline materials from molecular synthons, strong and directional interactions such as hydrogen-bonds (HBs) and halogen-bonds (XBs) have received much attention in recent years, ${ }^{1}$ due to the fact that the supramolecular architectures resulting from these interactions are quite robust and their topology can in theory be predicted.

However, it is also known that crystal structures are the result of a complex equilibrium among several factors, and small variations on the molecular shape and the strength and directionality of the intermolecular interactions involved can result in dramatic structural differences, thus influencing the predictability of a given supramolecular architecture. ${ }^{2}$ Especially in the case of $\mathrm{HBs}$ and $\mathrm{XBs},{ }^{3}$ which in some cases can show similar order of strength, ${ }^{1 \mathrm{a}}$ competition and cooperativity between these interactions can even more complicate the matter, being decisive in driving the outcome of a given crystal packing. ${ }^{4}$ Moreover, substituent effects are also very important in determining the energies of halogen bonding interactions and, therefore, the competition with other type of interactions. ${ }^{4 \mathrm{e}}$ The understanding of all these factors is then of primary importance to design new crystalline materials and to control their physical properties. ${ }^{5}$
Crystal structure comparison, especially when applied to family of related compounds, is an useful approach to investigate the tendency of a given molecule to form specific supramolecular architectures and in particular to understand how subtle variations in the molecular skeleton might affect the geometry and the hierarchy of intermolecular interactions influencing the resulting crystal structure. ${ }^{6}$ In this respect, several studies have been recently published ${ }^{7}$ and some of them have also applied the use of specific automated software to search for structural similarities. $^{8}$

Neutral Charge Transfer (CT) adducts between dihalogens, XY $(\mathrm{X}=\mathrm{Y}=\mathrm{I}, \mathrm{Br} ; \mathrm{X}=\mathrm{I}, \mathrm{Y}=\mathrm{Cl}, \mathrm{Br}$ ), and molecules containing chalcogen donor atoms, $\mathrm{E}(\mathrm{E}=\mathrm{S}$, Se), represent an important and extensively investigated class of compounds formally featuring an $\mathrm{E} \cdots \mathrm{X}-\mathrm{Y}$ halogen-bond (one of the earliest to be studied). ${ }^{9}$ They have attracted much interest, due to their potential relevance to material chemistry, biology and pharmacological activities, including anti-fungal and antibacterial properties, and particularly for their involvement in the mechanism of action of anti-thyroid drugs. ${ }^{10}$

However, the reaction between molecules containing chalcogen donor atoms and dihalogens can afford a great variety of products depending on the experimental conditions used, including the polarity of the solvents, the reaction molar ratio, the acid-base nature of the starting materials, and the chemical environment of the donor atoms. ${ }^{9}{ }^{11}$ Beside neutral "spoke” CT 
adducts featuring an almost linear $\mathrm{E}-\mathrm{X}-\mathrm{Y}$ moiety and formally a XB, insertion adducts containing a “T-shaped” $\mathrm{X}-\mathrm{E}-\mathrm{X}$ fragment and oxidation products of the donor molecules balanced by polyiodides of different complexity can also be obtained and their formation is not always predictable.9, 11 Interestingly, structural evidences suggest a common nature of the chemical bond in linear three-body systems involving either halogens, $\mathrm{X}-\mathrm{X}-\mathrm{X}(\mathrm{X}=\mathrm{Br}, \mathrm{I})$, or halogen(s) and chalcogen(s) atoms, $\mathrm{E}-\mathrm{X}-\mathrm{Y}, \mathrm{X}-\mathrm{E}-\mathrm{Y}$, and $\mathrm{E}-\mathrm{X}-\mathrm{E}(\mathrm{E}=\mathrm{S}$, Se; $\mathrm{X}=\mathrm{Y}=\mathrm{Cl}$, $\mathrm{Br}, \mathrm{I} ; \mathrm{X}=\mathrm{I}, \mathrm{Y}=\mathrm{Cl}, \mathrm{Br}, \mathrm{I}$ ) such as those in the above "spoke" and "T-shaped" dihalogen adducts, which can be successfully explained using the charge-transfer and 3c-4e models, thus supporting a covalent nature of the halogen-bond. ${ }^{12}$

CT adducts can be furthermore classified into four main groups depending on their structural features and stoichiometries. They can be simple (E-X-Y) or bridging adducts (E-X-Y-E), in both the chalcogen donor atom(s) interacts with the dihalogen molecule via XBs forming a 1:1 or 2:1 donor-to-dihalogen molecule stoichiometry, respectively. On the other hand, if the $\mathrm{E} \cdots \mathrm{X}$ interaction in a simple adduct is strong enough to determine a strong polarization of the dihalogen moiety $\left(\mathrm{E}-\mathrm{X}^{\delta^{+}}\right.$ $\cdots \mathrm{Y}^{\delta-}$ ) the partially negative terminal halogen atom can act as donor, interacting with another dihalogen molecule, thus forming more complex systems defined as amphoteric adducts $(\mathrm{E}-\mathrm{X}-\mathrm{Y}-\mathrm{X}-\mathrm{Y})$ or bridging amphoteric adducts $\left[\mathrm{E}-(\mathrm{X}-\mathrm{Y})_{\mathrm{n}}-\mathrm{E}\right]$, respectively, with different pathways in the halogen-halogen and chalcogen-halogen bond lengths. ${ }^{9,11,13}$

Generally, the structural features and supramolecular architectures of dihalogen CT and "T-shaped" adducts are also determined by soft $\cdots$ soft chalcogen $\cdots$ halogen and halogen $\cdots$ halogen interactions in cooperation with $\mathrm{XBs},{ }^{14}$ and the understanding of the interplay of all these interactions in connection with the molecular donor shape could be of help in predicting either the archetypes of products ensuing from the reaction of dihalogens and chalcogen donors or their crystal packing features.

Starting from these considerations and bearing in mind the structural complexity of the supramolecular architectures in dihalogen CT adducts of chalcogen donor molecules, we decided to study the crystal structure of a family of related molecular adducts based on chalcogen donors and dihalogens, with the aim to investigate the competitive and/or cooperative role of HBs and XBs and to explore the influence of differences at molecular level in the resulting crystal structures. Here we report the synthesis and the structural comparison of three new molecular CT adducts with dihalogens (13), based on 5,5-dimethyl-2-thiohydantoin (dth) and 1,5,5-trimethyl2-thiohydantoin (mdth) donors. ${ }^{15}$ We have extended the structural comparison to related adducts previously reported by some of the authors that from a search in the Cambridge Structural Database (CSD: ConQuest version $1.19,2016)^{16}$ result to be the only published crystal structures of analogous derivatives. The search was performed on all molecular adducts with a common dimethylimidazolidine skeleton substituted in the positions 2 and 4 of the pentatomic ring with any chalcogen $(\mathrm{O}, \mathrm{S}, \mathrm{Se}, \mathrm{Te})$, finding a total of four additional crystal structures (4-7) based on 5,5dimethylimidazolidine-2,4-dithione (ddth), 5,5-dimethyl-2- thiohydantoin (dth) and 5,5-dimethyl-2-selenoimidazolidine-4-one (dsh) donors (CSD ref codes: KUWDEL, KUWDIP, KUWDOV and KUWDUB $)^{15}$ as reported in Scheme 1 . The search was also extended to adducts of related dialkyl-imidazolidines, but no additional items were found. Finally, we have analyzed energetically the HBs and XBs in these compounds using $a b$ initio calculations, focusing on cooperativity effects between both types of interactions.

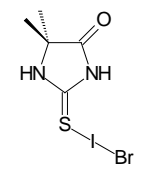

[(dth)IBr] (1)

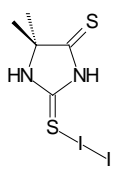

[(ddth) $\left.\left.\right|_{2}\right](4)$ ref. code: KUWDEL

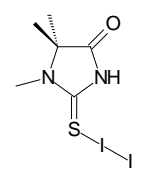

[(mdth) $\left.\mathrm{I}_{2}\right](2)$

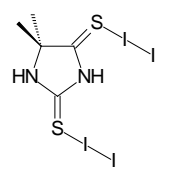

[(ddth) $\left.\left(\mathrm{I}_{2}\right)_{2}\right](5)$ ref. code: KUWDIP

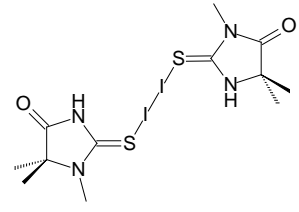

[(mdth) $\left.\left.{ }_{2}\right|_{2}\right](3)$

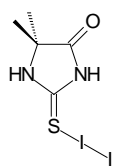

[(dth) $\left.I_{2}\right](6)$ ref. code: KUWDOV

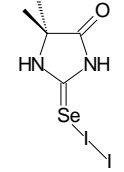

$\left[\left.(\mathrm{dsh})\right|_{2}\right](7)$ ref. code: KUWDUB
Scheme 1. Family of CT dihalogen adducts with donor molecules containing chalcogen atoms considered in this paper.

\section{Results and discussion}

Structural analysis: molecular units. Crystals of compounds 1-3 suitable for X-ray diffraction analysis were obtained from $\mathrm{CH}_{2} \mathrm{Cl}_{2}$ solutions of the appropriate donor and dihalogen molecules by slow evaporation (see Experimental Section). Micro-analytical data indicated a 1:1 donor/dihalogen stoichiometry for $\mathbf{1}$ and 2, and a 2:1 stoichiometry for $\mathbf{3}$. The presence of only one main peak in the FT-Raman spectra of 1-3 at values ( $v=179,152$, and $173 \mathrm{~cm}^{-1}$, respectively) lower than those corresponding to the stretching frequencies of the solid $\mathrm{I}_{2}$ and $\operatorname{IBr}\left(v=180\right.$ and $216 \mathrm{~cm}^{-1}$, respectively), indicated the formation of CT adducts having weak or medium-weak nature with $\Delta d(\mathrm{I}-\mathrm{Y})$ lower than $0.18 \AA\left[\Delta d(\mathrm{I}-\mathrm{Y})=d(\mathrm{I}-\mathrm{Y})_{\text {adduct }}-\right.$ $\left.d(\mathrm{I}-\mathrm{Y})_{\text {gas phase }}\right]^{13 a}$ An $\mathrm{X}$-ray diffraction analysis was, therefore undertaken to ascertain the nature of compounds 1-3.

Crystal data and other experimental details are summarized in Table 1S (Electronic Supplementary Material, ESI) ${ }^{\dagger}$ together with the basic unit cell parameters, including the donor/dihalogen stoichiometry of the previously published selected structures 4-7.

The X-ray analysis confirmed the stoichiometry and the CT adduct nature for 1-3. Both $\mathbf{1}$ and $\mathbf{2}$ are discrete CT adducts in which the $\mathrm{S}$ atom binds the dihalogen molecule in the plane of the pentatomic ring to give a linear $\mathrm{S}-\mathrm{I}-\mathrm{Br}$ and $\mathrm{S}-\mathrm{I}-\mathrm{I}$ arrangement, respectively [S $\cdots$ I 2.587(3), I-Br 2.744(2) Å, SI-Br 173.43(6) ${ }^{\circ}$, for 1; S $\cdots I$ 2.818(2), I-I 2.795(1) $\AA$, S-I-I $178.03(3)^{\circ}$ for 2] (Table 1, Fig. 1S, ESI) ${ }^{\dagger}$. In both compounds the $\mathrm{I}-\mathrm{X}(\mathrm{X}=\mathrm{Br}$ for $\mathbf{1}$, and $\mathrm{I}$ for 2 ) bond distance is lengthened with respect to the gaseous IX molecule, ${ }^{13 a}$ as a result of the electron density donation from a non-bonding orbital of the chalcogen donor atom into the $\sigma^{*}$ LUMO of the IX molecule lying along the $\mathrm{I}-\mathrm{X}$ axis. In $\mathbf{3}$, the $2: 1$ donor/dihalogen 
stoichiometry is confirmed via the formation of a bridging CT adduct lying on an inversion center with the $\mathrm{I}_{2}$ molecule being almost perpendicular to the plane of the pentatomic rings and weakly interacting at the $S$ atoms of two donor molecules [S $\cdots I$ 3.171(1), I-I $\mathrm{I}^{\mathrm{i}}$ 2.751(1) $\AA$, S-I-I 175.83(2) $\left.{ }^{\circ}, \mathrm{i}=1-\mathrm{x}, 1-\mathrm{y}, 2-\mathrm{z}\right]$ (Table 1, Fig. 1S, ESI) ${ }^{\dagger}$. As expected, the dative influences of the two donor molecules are mutually exclusive and leave the bridging $\mathrm{I}_{2}$ molecule in $\mathbf{3}$ only slightly perturbed with respect the case of a simple or 1:1 "spoke" adduct such as $2 .{ }^{17}$

In order to have a better idea of the factors determining the crystal packing in these compounds, a comparison with the adducts 4-7 featuring a similar hydantoin-like skeleton for the donor molecules was performed.

Although the CT adduct units in 1-7 have both a similar molecular shape (Scheme 1), and a similar set of HBs and XBs donors and acceptors, the seven structures exhibit major differences in the crystal packing (see below).

First of all, the small differences at molecular level of the donor molecules in 1-7 seem to have a significant influence on the geometry of the E-I-Y moiety within the CT adduct units. In the majority of the structures the E $\cdots \mathrm{I}-\mathrm{Y}$ interaction lies on the same plane as the pentatomic ring of the hydantoin framework, differing only for the orientation of the E-I-Y axis (Fig. 1a-g), which is on the same side of the $\mathrm{C}=\mathrm{O}$ group for structure 2 (Fig. 1b) and on the opposite side of the $\mathrm{C}=\mathrm{O}$ (or $\mathrm{C}=\mathrm{S}$ in position 4 of the ring) group for the structures $(\mathbf{1}, \mathbf{4}, \mathbf{6}, \mathbf{7})$. In compound 5 (Fig. 1e), both $\mathrm{C}=\mathrm{S}$ groups interact with one $\mathrm{I}_{2}$ molecule in the plane of the pentatomic ring.

Table 1. Distances, geometry, sum of the van der Waals radii $\left(r_{w} E+r_{w} X\right)$ and reduction of the sum of the van der Waals radii $\left(R_{v d W} \%\right)$ for the $E-X-Y$ halogen bonds. For structure 5 details are reported for both halogen bonds observed ( $a$ and $b$ respectively).

\begin{tabular}{|l|l|l|l|l|l|}
\hline & $\mathbf{E}-\mathbf{X}(\boldsymbol{\AA})$ & $\mathbf{X}-\mathbf{Y}(\boldsymbol{\AA})$ & $\mathbf{E}-\mathbf{X}-\mathbf{Y} \mathbf{(}^{\mathbf{}} \mathbf{)}$ & $\mathbf{r}_{\mathbf{w}} \mathbf{E}+\mathbf{r}_{\mathbf{w}} \mathbf{X}(\boldsymbol{\AA})$ & $\mathbf{R v d W}$ \% \\
\hline $\mathbf{1}$ & $2.587(3)$ & $2.744(2)$ & $173.43(6)$ & 3.65 & 29 \\
\hline $\mathbf{2}$ & $2.818(2)$ & $2.795(1)$ & $178.03(3)$ & 3.78 & 25 \\
\hline $\mathbf{3}$ & $3.171(1)$ & $2.751(1)$ & $175.83(2)$ & 3.78 & 16 \\
\hline $\mathbf{4}$ & $2.748(1)$ & $2.817(1)$ & $176.88(2)$ & 3.78 & 27 \\
\hline $\mathbf{5 ( a )}$ & $2.738(1)$ & $2.848(1)$ & $177.94(4)$ & 3.78 & 28 \\
\hline $\mathbf{5 ( a )}$ & $2.843(1)$ & $2.767(1)$ & $173.74(4)$ & 3.78 & 25 \\
\hline $\mathbf{6}$ & $2.773(1)$ & $2.802(1)$ & $176.14(2)$ & 3.78 & 27 \\
\hline $\mathbf{7}$ & $2.699(1)$ & $2.962(2)$ & $173.84(2)$ & 3.88 & 30 \\
\hline
\end{tabular}

${ }^{a}$ the van der Waals radii considered are those reported in ref. 18 .

The different conformation observed in $\mathbf{2}$ depends on the presence of a methyl group attached to the nitrogen atom $\mathrm{N}(2)$ that forces the formation of the ancillary $\mathrm{N}-\mathrm{H} \cdots \mathrm{I}$ bond at the $\mathrm{N}(1)$ side (Fig. 1S) ${ }^{\dagger}$. In 3 , the S-I-I axis lies approximately perpendicular to the pentatomic ring (Fig. $1 \mathrm{c}$ ) resulting in an "orthogonal” conformer.

The observation of "parallel" and "orthogonal” conformers is not uncommon in CT adducts of dihalogens and heterocyclic chalcogen donors, ${ }^{9,19}$ however the major differences between 2 and $\mathbf{3}$, both featuring the common mdth moiety as donor, confirm the structural unpredictability in this class of compounds. (a)

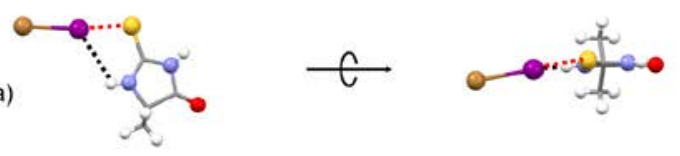

(b)
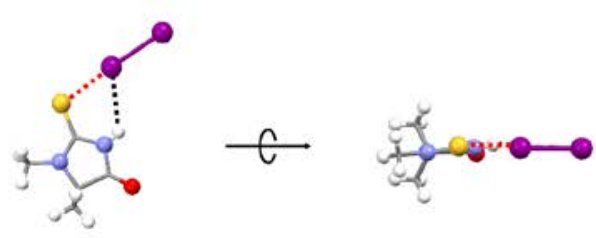

(c)
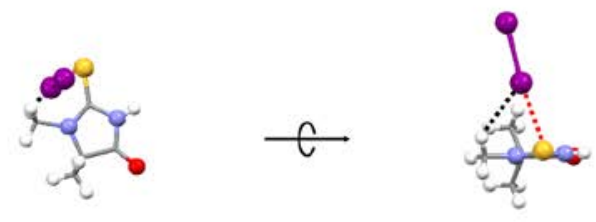

(d)
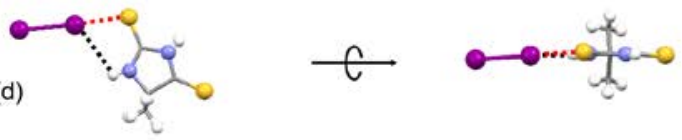

(e)
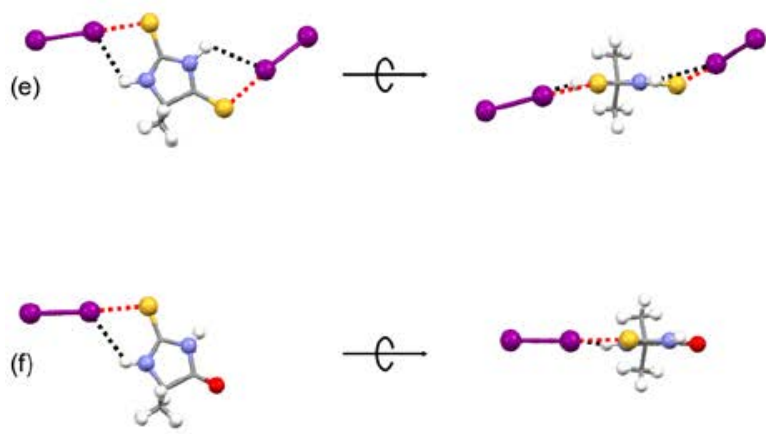

(g)
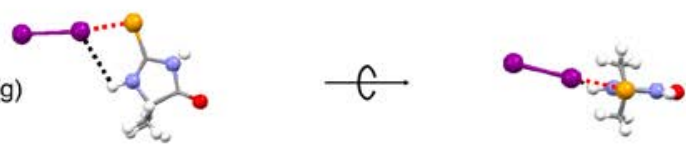

Fig. 1. Geometry of the CT adducts units viewed along two orthogonal directions for compounds 1-7 (a-g, respectively). XBs and ancillary $\mathrm{N}-\mathrm{H} \cdots \mathrm{X}$ interactions are indicated as red and black dashed lines, respectively.

As described below, the energies calculated for the two conformers show similar values and the different situation observed in $\mathbf{2}$ and $\mathbf{3}$ might be related to the different stoichiometry adopted by the two complexes (1:1 and 2:1 donor/dihalogen, respectively).

In particular, to form a 2:1 stoichiometry adopting a "parallel” conformation for the S-I-I frameworks, the system would have 
to break the centrosymmetric dimer of donor molecules in $\mathbf{2}$ (see below) and this could not be energetically favorable, making the "orthogonal" conformer more suitable for this stoichiometry in $\mathbf{3}$.

The intramolecular distances for the structures $\mathbf{2}$ and 4-6 lie in the range 2.738(1)-2.843(1) $\AA$ for the $S \cdots X$ interaction, and 2.751(1)-2.848(1) $\AA$ for the I-I bond length (Table 1). This is not the case for structures 1 and 7 which show very short S $\cdots$ I and Se $\cdots$ I distances, respectively, and for structure $\mathbf{3}$, in which the $\mathrm{S} \cdots \mathrm{I}$ distance is significantly longer indicating a weaker CT interaction. The reduction of the sum of the van der Waals radii (RvdW \%) for the E...I interaction vary from 16\% in 3 to $30 \%$ in 7 (Table 1).

In 1, the observed strong S $\cdots$ I interaction might be explained considering that differently from the other structures considered, this is the only one involving the Lewis acid $\mathrm{I}-\mathrm{Br}$ that is a better acceptor than $\mathrm{I}_{2} \cdot{ }^{9}$ In fact, as described below, in this case the higher electronegativity of the $\mathrm{Br}$ atom increases the partial positive charge on the $\sigma$ hole of the I atom, which consequently forms a stronger interaction with the $\mathrm{S}$ donor atom. In the case of $\mathbf{7}$, the shorter E $\cdots$ I distance if compared to 6 might depend on several reasons. However, it interesting to note that the Lewis basicity of $\mathrm{C}=$ Se group is generally higher than $\mathrm{C}=\mathrm{S}$ donors, as also confirmed by calculations (see below). In the case of $\mathbf{3}$, the only one in the family featuring a $\mathrm{I}_{2}$ unit bridging two donor molecules, the increased $\mathrm{S} \cdots \mathrm{I}$ distance is in agreement with previous studies for bridging $I_{2}$ adducts and with the Charge Transfer model for the explanation of the nature of the chemical bonding in these systems. ${ }^{16}$

In all structures, but 3 , the $\mathrm{E} \cdots \mathrm{I}-\mathrm{Y} \mathrm{XB}$ is assisted by an intramolecular ancillary $\mathrm{N}-\mathrm{H} \cdots \mathrm{X} \quad \mathrm{HB}$ interaction $[\mathrm{N} \cdots \mathrm{X}$ distances in the range $3.474(5)-3.697(6) \AA$, Table $2 S]^{\dagger}$. This interaction is not observed in adduct $\mathbf{3}$ which adopts an "orthogonal" conformation which seems to be stabilized by a weak $\mathrm{C}-\mathrm{H} \cdots \mathrm{I}$ intramolecular interaction with the adjacent methyl group [C $\cdots$ I distance 3.959(3) $\AA$, Table $2 \mathrm{~S}]^{\dagger}$, as shown in Figure 1c, and confirmed by theoretical calculations (see below).

Structural analysis: crystal packings. In all structures (1-4, 6-7) with the only exception of $\mathbf{5}$, donor molecules arrange in centrosymmetric dimers via $\mathrm{N}-\mathrm{H} \cdots \mathrm{E}$ HB interactions involving the imidazolidine $\mathrm{H}$-donor $\mathrm{NH}$ in position 3 and the $\mathrm{H}$-acceptor $\mathrm{C}=\mathrm{E}$ in position 4 (where $\mathrm{E}=\mathrm{O}$ or $\mathrm{S}$, see scheme 1). This is not observed in 5 since both $\mathrm{C}=\mathrm{S}$ groups are involved in the formation of a XB with $\mathrm{I}_{2}$ giving a 1:2 donor/dihalogen adduct. For the structures 1-3, 6 and 7 , featuring the $\mathrm{C}=\mathrm{O}$ group in position 4 of the donor molecules, the $\mathrm{N}-\mathrm{H} \cdots \mathrm{O}$ distances are in the range $2.00-2.15 \AA$ [the range for $\mathrm{N} \cdots \mathrm{O}$ distance is 2.848(11)-2.935(5) $\AA$, Table $2 \mathrm{~S}$ in the ESI $]^{\dagger}$. In the case of 4 , the $\mathrm{N}-\mathrm{H} \cdots \mathrm{S}$ distance [2.58(3) $\AA$ ] is slightly longer $[\mathrm{N} \cdots \mathrm{S}$ distance 3.362(3) $\AA$ ] (Table 2S, ESI) ${ }^{\dagger}$. The dimeric arrangements of donor molecules further interact via XBs and HBs determining different types of supramolecular architectures in the crystal lattice. As suggested by theoretical calculations (see below), the formation of $\mathrm{N}-\mathrm{H} \cdots \mathrm{E} \mathrm{H}$-bonded dimeric arrangement of donor molecules results in a reinforcement of the $E \cdots X-Y$ XBs thus suggesting the existence of a cooperative effect in most of the structures between these two kind of main interactions.

In $\mathbf{1}$, the dth dimers are connected to each other by $\mathrm{C}-\mathrm{H} \cdots \mathrm{O}$ interactions of $2.55 \AA$ [C $\cdots$ O distance is 3.413(15) $\AA$, Table $2 S]^{\dagger}$ to form zig-zag chains developing along the $a$ direction (Figs. 2a and 2b). These chains are connected to adjacent chains through the dihalogen moiety by S $\cdots$ I XBs, and $\mathrm{N}-\mathrm{H} \cdots \mathrm{Br}$ HBs $[\mathrm{N} \cdots \mathrm{Br} 3.480(9)$ $\AA$ ] resulting in $2 \mathrm{D}$ sheets (Fig. 2a) which are packed along the third dimension (Fig. 2b) by weak $\mathrm{C}-\mathrm{H} \cdots \mathrm{Br}$ interactions $[\mathrm{C} \cdots \mathrm{Br}$ distances is 3.749(12) $\AA$, Table 2S $]^{\dagger}$.

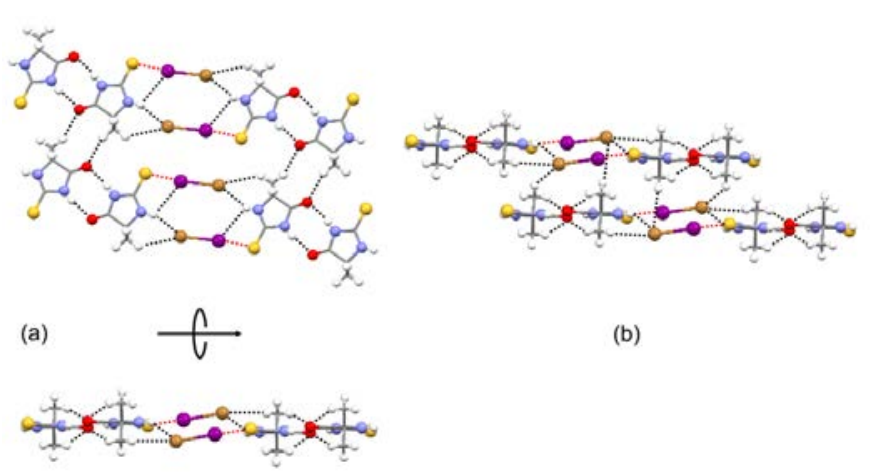

Fig. 2. Partial view of $2 \mathrm{D}$ sheets in 1 ; (a) the $2 \mathrm{D}$ arrangement is viewed along two orthogonal directions; (b) propagation of the 2D sheet along the $b$-c direction. $\mathrm{XBs}$ and $\mathrm{HBs}$ are indicated as red and black dashed lines, respectively.

An identical assembly is observed in 7 which basically adopts the same crystal packing of $\mathbf{1}$. Similarly to 1 (Fig. 2a and Fig. 3a), in $\mathbf{7}$ the centrosymmetric dimers of $\mathbf{d s h}$ molecules develop along the $a$ direction via weak $\mathrm{C}-\mathrm{H} \cdots \mathrm{O}$ interactions of 2.74(5) $\AA$ forming zig-zag chains [C $\cdots \mathrm{O}$ distance $3.076(7) \AA$, Table $2 \mathrm{~S}]^{\dagger}$. (a)

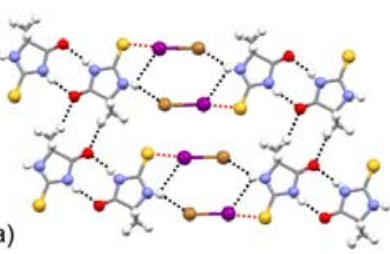

(c)

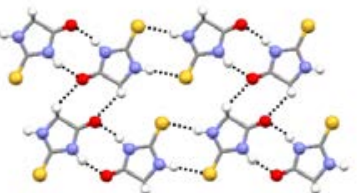

(d)
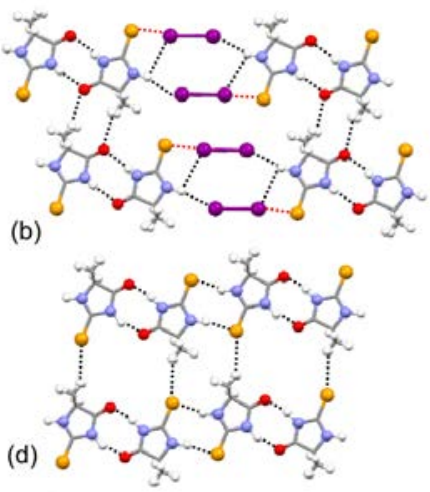

(e)

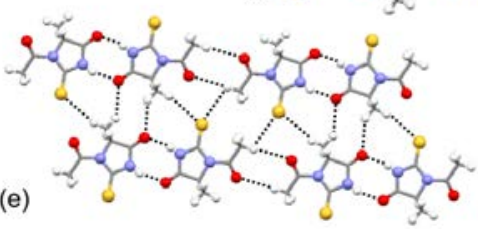

Fig. 3. Partial view of 2D sheets in: (a) 1; (b) 7; (c) th (THHYDTO2); (d) dsh (FILXIH) and (e) amth (DIKWAW). S-I XBs and HBs are indicated as red and black dashed lines, respectively.

Adjacent chains are bridged by $I_{2}$ moieties along the $b$ - $c$ direction, to form the $2 \mathrm{D}$ arrangement reported in Fig. 3b. The 
2D sheets are connected along the third dimension via two weak $\mathrm{C}-\mathrm{H} \cdots \mathrm{I}$ interactions involving the $\mathrm{I}_{2}$ and the methyl groups [C $\cdots$ I distances are 4.124(7) and 4.148(5) $\AA$, Table $2 \mathrm{~S}]^{\dagger}$.

Similar 2D arrangements (Fig. 3 c-e) are also observed in the crystal packing of three imidazolidine derivatives having a skeleton similar or equal to that of the donor molecules in the CT adducts 1-7: 2thioxoimidazolidin-4-one (th) ${ }^{20}$ 5,5-dimethyl-2selenoxoimidazolidin-4-one (dsh) ${ }^{21}$ and 1-acetyl-5-methyl-2thioxoimidazolidin-4-one (amth) ${ }^{22}$ (CSD ref codes: THHYDT02, FILXIH and DIKWAW, respectively). With reference to the crystal structures of th and dsh, the coordinated $\mathrm{IBr}$ and $\mathrm{I}_{2}$ molecules in $\mathbf{1}$ and 7, respectively, simply act as bridges between adjacent $1 \mathrm{D}$ zigzag chains of donor molecule dimers, formally by insertion in the $\mathrm{N}-\mathrm{H} \cdots \mathrm{S}$ /Se HBs which held the 2D sheets of th and $\mathbf{d s h}$ dimers in the structures THHYDT02 and FILXIH, and thus forming N-H $\cdots \mathrm{I}-$ $\mathrm{I} / \mathrm{Br} \cdots \mathrm{S} / \mathrm{Se}$ arrangements. The $\mathrm{IBr}$ and $\mathrm{I}_{2}$ molecules behave as $\mathrm{XB}$ donors on one side towards the chalcogen atom, and as HB acceptor on the other side towards the $\mathrm{NH}$ group, thus mimicking the set of inter-chain HBs observed in THHYDT02 and FILXIH [N-H $\cdots$ S for THHYDT02 and N-H $\cdots$ Se in FILXIH are 2.402(1) and 2.54(17) $\AA$, respectively]. Our calculations (see below) show that the insertion of $\mathrm{I}_{2}$ molecules in the $\mathrm{N}-\mathrm{H} \cdots$ Se dimers observed in FILXIH to form the $\mathrm{N}-\mathrm{H} \cdots \mathrm{I}-\mathrm{I} \cdots$ Se bridged dimers observed in 7 is energetically favourable. Presumably, this common 2D arrangement is the result of the similar strength and directionality of the cooperative set of $\mathrm{N}-$ $\mathrm{H} \cdots \mathrm{I}-\mathrm{I} / \mathrm{Br} \cdots \mathrm{S} / \mathrm{Se}$ in $\mathbf{1}$ and $\mathbf{7}$ and the $\mathrm{N}-\mathrm{H} \cdots \mathrm{S} / \mathrm{Se} \mathrm{HBs}$ in THHYDT02, FILXIH and DIKWAW, combined with the similar molecular shape of the donor molecules.

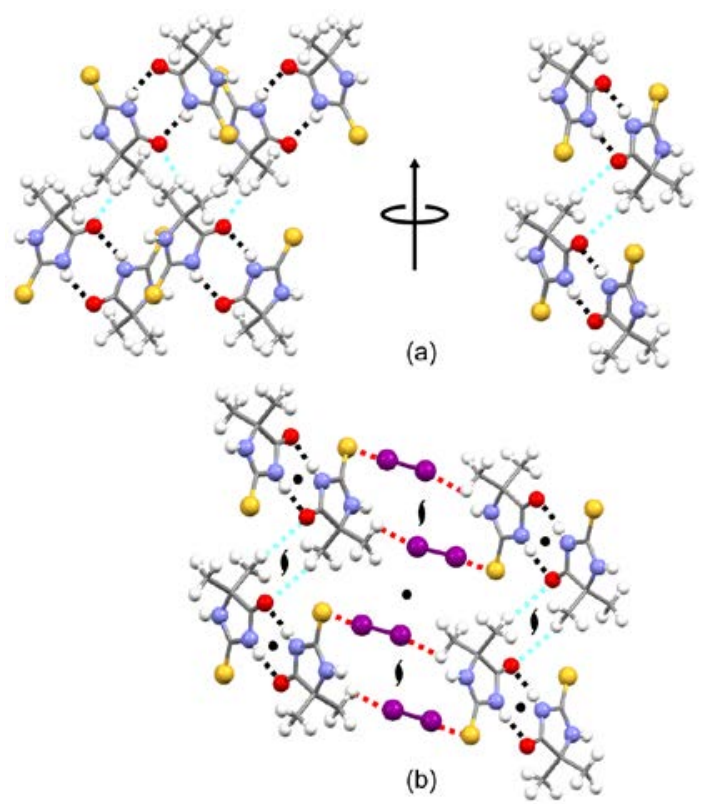

Fig. 4. Main intermolecular interactions connecting centrosymmetric adduct dimers in 6. (a) $\mathrm{N}-\mathrm{H} \cdots \mathrm{O}$ and $\mathrm{C}-\mathrm{H} \cdots \mathrm{O}$ weak $\mathrm{HBs}$ viewed along two orthogonal projections (b) $\mathrm{S} \cdots|-| \cdots \mathrm{H}-\mathrm{C}$ bridges. $\mathrm{N}-\mathrm{H} \cdots \mathrm{O}$ and $\mathrm{C}-\mathrm{H} \cdots \mathrm{O}$ interactions are indicated as black and cyan dashed lines, respectively. S $\cdots|-| \cdots H-C$ interactions are indicated as red dashed lines. $2_{1}$ screw axes and center of inversion are also reported.

This is not a general rule, as shown by the structure of $\mathbf{6}$. In this case in fact, though the crystal packing shows common features with those of both 1 and 7, including a very similar set of intermolecular interactions, the resulting supramolecular architecture is consistently different.

Similarly to structures $\mathbf{1}$ and 7 , the centrosymmetric $\mathrm{N}-\mathrm{H} \cdots \mathrm{O}$ bonded dimers [N $\cdots \mathrm{O}$ distance 2.874(4) $\AA$, Table $2 \mathrm{~S}]^{\dagger}$ of dth units in 6 interact with adjacent dimers via two main set of interactions: weak $\mathrm{C}-\mathrm{H} \cdots \mathrm{O} \mathrm{HBs}[(\mathrm{C} \cdots \mathrm{O}$ distance 3.559(6) $\AA$ ] $]$ and a cooperative pair of XBs and HBs within S-I-I $\cdots \mathrm{H}-\mathrm{C}$ frameworks [C $\cdots$ I distance 3.682(5) A, Table 2S $]^{\dagger}$ involving the dihalogen moieties as bridges (Fig. 4). However, instead of forming flat 2D sheets, the molecules are assembled adopting a herringbone type packing, with different dimers related by $2_{1}$ screw axes (Fig. $4 \mathrm{~b}$ ).

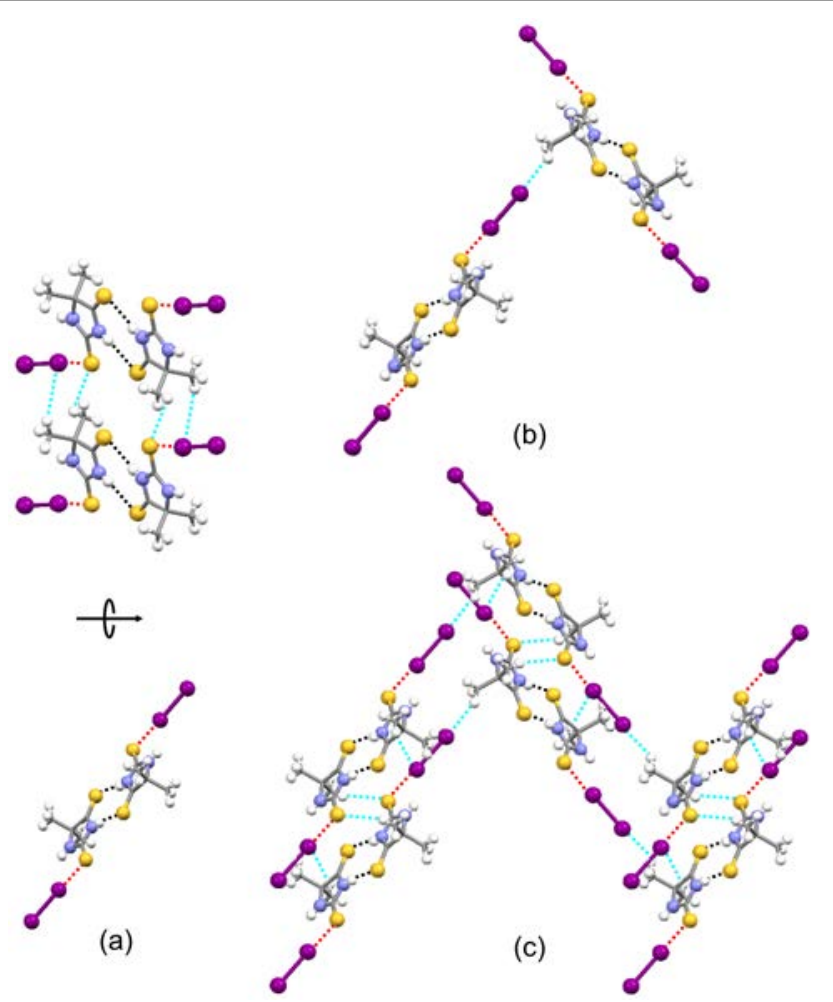

Fig. 5. Main intermolecular interactions in 4. (a) Projection of the 1D chain viewed along the two directions: $a$ (top) and $c$ (bottom); (b) connected adjacent 1D chains viewed down the $c$ direction; (c) packing of 1D chains viewed down the c direction. $\mathrm{C}-\mathrm{H} \cdots \mathrm{I}$ and $\mathrm{C}-\mathrm{H} \cdots \mathrm{S}$ interactions are indicated as cyan dashed lines, $\mathrm{S} \cdots \mathrm{I}-\mathrm{I}$ halogen bonds are indicated as red dashed lines, and $\mathrm{N}-\mathrm{H} \cdots \mathrm{O}$ hydrogen bonds as black dashed lines.

In 4, the centrosymmetric $\mathrm{N}-\mathrm{H} \cdots \mathrm{S}$ [N $\cdots \mathrm{S}$ distance 3.362(3) $\AA$ ] bonded dimers of ddth donor molecules are assembled along the $a$ c direction via $\mathrm{C}-\mathrm{H} \cdots \mathrm{S}$ interactions involving the methyl groups and the sulfur atoms [C $\cdots$ S distance is $3.570(4) \AA]$, supported by weak C-H $\cdots$ I interactions [C $\cdots$ I distance is $4.177(4) \AA$, Table $2 \mathrm{~S}]^{\dagger}$ to form a $1 \mathrm{D}$ arrangement similar to the zig-zag chains described for $\mathbf{1}$ and 7 (Fig. 5a). The terminal iodine atoms of the coordinated $I_{2}$ molecules are also involved in bridging different instances of this $1 \mathrm{D}$ arrangement via $\mathrm{C}-\mathrm{H} \cdots \mathrm{I}$ HBs interactions which lie parallel to the 
S $\cdots$ I-I axis [C $\cdots$ I distances $3.634(4) \AA]$. The relative orientation of adjacent instances of the $1 \mathrm{D}$ chains is approximately perpendicular resulting in a $2 \mathrm{D}$ herringbone motif, which develops along the $b$ direction (Fig. 5b). These 2D arrangements develop along the $a$ direction (Fig. $5 \mathrm{c}$ ) via a set of $\mathrm{C}-\mathrm{H} \cdots \mathrm{S}$ and $\mathrm{C}-\mathrm{H} \cdots \mathrm{I}$ interactions still involving the methyl groups [C $\cdots \mathrm{S}$ distance is 3.998(5) $\AA$; $\mathrm{C} \cdots \mathrm{I}$ distances are 4.154(4) $\AA$ and 4.217(4) $\AA$, Table 2S $]^{\dagger}$.

When the ddth donor interacts with two equivalents of $I_{2}$ the resulting crystal structure of the 1:2 adduct, 5, shows a different arrangement in the solid state compared with the 1:1 analogue adduct 4 . In this case the formation of the $\mathrm{N}-\mathrm{H} \cdots \mathrm{S}$ centrosymmetric dimer is not allowed because both $\mathrm{C}=\mathrm{S}$ groups are involved in XBs with $I_{2}$ molecules. A view of 5 with hidden $I_{2}$ molecules (Fig. 6a) evidences adjacent ddth molecules connected via a set of $\mathrm{C}-\mathrm{H} \cdots \mathrm{S}$ interactions [C $\cdots \mathrm{S}$ distances are 3.951(7) and 4.110(8) $\AA$, respectively] to form a $2 \mathrm{D}$ herringbone arrangement parallel to the $b c$ plane. These 2D sheets are bridged each other along the $a$ direction by the two bonded halogen molecules (Fig. 6b) which interact via a set of $\mathrm{N}-\mathrm{H} \cdots \mathrm{I}$ interactions [N $\cdots \mathrm{I}$ distances are 3.748(5) and 3.903(5) $\AA$, respectively] that for one dihaalogen molecule are also supported by a set of weak $\mathrm{C}-\mathrm{H} \cdots \mathrm{I}$ interactions $[\mathrm{C} \cdots \text { I distance is 4.058(7) } \AA \text {, Table 2S }]^{\dagger}$.

We have also compared the structures of $\mathbf{4}$ and $\mathbf{5}$ with that of the donor molecule ddth (ref. CCDC code FILXED). ${ }^{21}$ Differently from the case of structures $\mathbf{1}$ and $\mathbf{7}$ which show a common 2D architecture similar to that observed in the crystal structure of the donor molecule dsh (Fig. 3), in the case of ddth, the absence of $\mathrm{I}_{2}$ as compared to $\mathbf{4}$ and 5 determines major differences in the crystal packing (see Figs. 2Sd and 2Se, ESI) ${ }^{\dagger}$, The only common feature observed in $\mathbf{4}$ and ddth is a similar stack along the $a$ direction of centrosymmetric $\mathrm{N}-\mathrm{H} \cdots \mathrm{S}$ bonded dimers of ddth and ddth $\mathrm{I}_{2}$ units, respectively (Figs. 2Sd and 2Se, ESI) ${ }^{\dagger}$.

In 2, the presence of the methyl group bound to the nitrogen atom $\mathrm{N}(2)$ and consequently the different geometry adopted by the S-I-I framework (Fig 1) strongly influences the possibility of assembling mdth dimers in zig-zag chains or 1D architectures analogous to those described above.
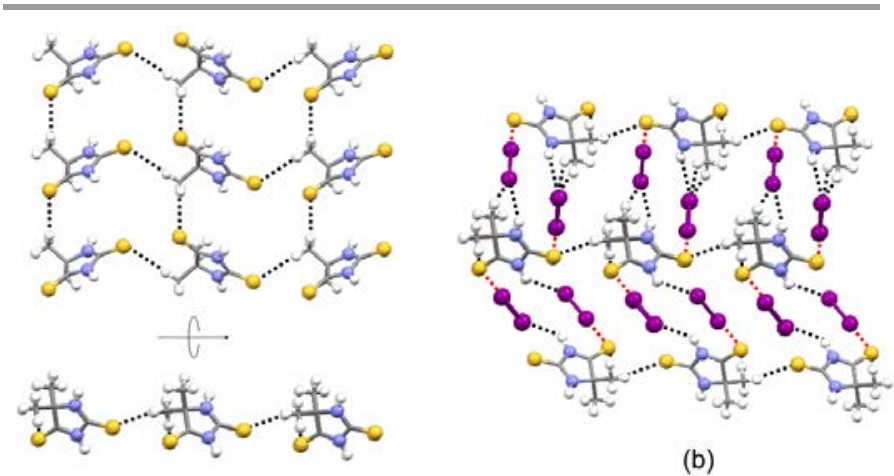

(a)

Fig. 6. Main intermolecular interactions in 5. (a) 2D herringbone arrangement of ddth units connected via $\mathrm{C}-\mathrm{H} \cdots \mathrm{S}$ interactions ( $\mathrm{I}_{2}$ molecules omitted) viewed along the $a$ direction (top) and along the $b$ direction (bottom); (b) packing of the $2 \mathrm{D}$ herringbone arrangements of the $\mathrm{CT}$ adducts along the $a$ axis viewed along the $b$ direction. $\mathrm{N}-\mathrm{H} \cdots \mid$ and $\mathrm{C}-\mathrm{H} \cdots 1 \mathrm{HBs}$ are represented as black dashed lines, $\mathrm{S} \cdots \mid \mathrm{XBs}$ are represented as red dashed lines.
The conformation adopted by the S-I-I framework with respect to the plane of the pentatomic ring prevents any $\mathrm{HB}$ interaction along directions parallel to the pentatomic ring, exception made for the $\mathrm{N}-$ $\mathrm{H} \cdots \mathrm{O}$ interactions forming the centrosymmetric mdth dimers. As a consequence in structure $\mathbf{2}$ the centrosymmetric mdth dimers are uniquely bridged by $\mathrm{I}_{2}$ molecules via a set of weak S $\cdots \mathrm{I}$ XBs [S $\cdots \mathrm{I}$ distance is $3.751(2) \AA$ ] supported by weak C-H $\cdots$ I interactions [C $\cdots$ I distances are 4.275(5) $\AA, 4.159(5) \AA$ and 4.125(4) $\AA$, Table $2 \mathrm{~S}]^{\dagger}$. Adjacent dimers develop along the $b$ and the $c$ directions, related by $2_{1}$ screw axes and by $c$-glides, respectively, to form a $2 \mathrm{D}$ herringbone arrangement (Fig 7a). This is then assembled along the $a$ direction by bridges of $\mathrm{I}_{2}$ (Fig $7 \mathrm{~b}$ ) connecting adjacent instances of the $2 \mathrm{D}$ arrangement.

It is worth noting how a small difference in the molecular skeleton of the donor molecule can generate dramatic structural differences between structure $\mathbf{2}$ and the two structures $\mathbf{1}$ and $\mathbf{7}$ described above (Fig. 2 and 3).

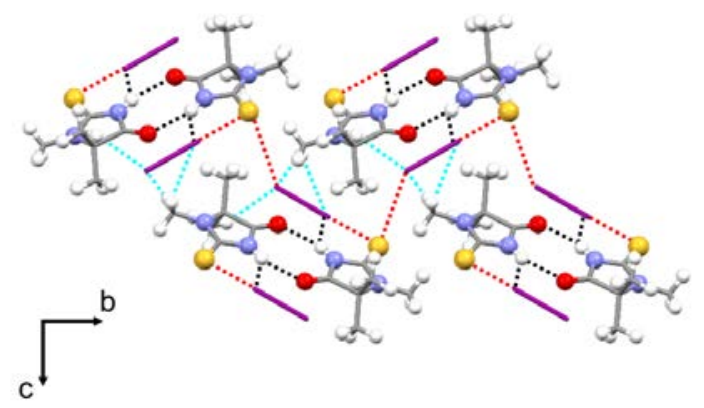

(a)

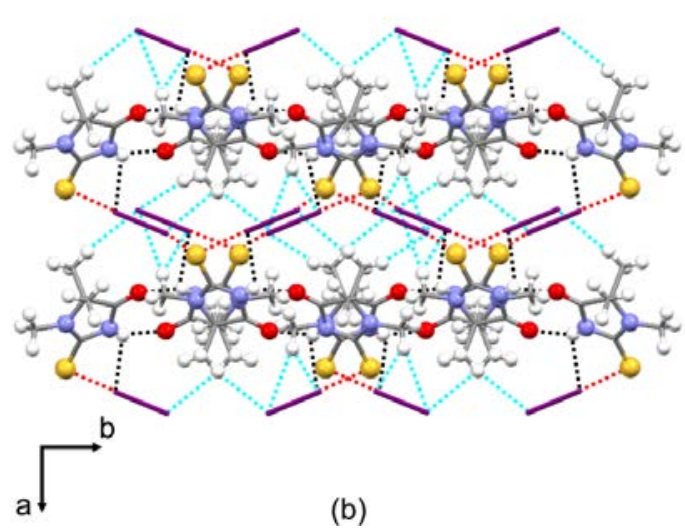

Fig. 7. Main molecular arrangement observed in 2. (a) $2 \mathrm{D}$ herringbone arrangement viewed along the $a$ direction ; (b) crystal packing of $\mathbf{2}$ viewed along the $c$ direction. $\mathrm{C}-\mathrm{H} \cdots \mathrm{l}$ interactions are indicated as cyan dashed lines, $\mathrm{N}-\mathrm{H} \cdots \mathrm{O}$ and $\mathrm{N}-\mathrm{H} \cdots \mathrm{I} \mathrm{HBs}$ are represented as black dashed lines and $\mathrm{S} \cdots \mathrm{I}$ XBs are represented as red dashed lines.

Differently from 2, in 3 the "orthogonal” conformation adopted by the $\mathrm{S}-\mathrm{I}-\mathrm{I}$ framework exposes the $\mathrm{C}=\mathrm{S}$ group and the methyl $\mathrm{CHs}$ along directions approximately parallel to the plane of the pentatomic ring. This allows the centrosymmetric mdth dimers to interact each other via weak $\mathrm{C}-\mathrm{H} \cdots \mathrm{S}$ interactions [C $\cdots$ S distance $3.907(3) \AA]$ to form $1 \mathrm{D}$ rows propagating along the $a$ direction, similar to those observed for $\mathbf{1}$ and $\mathbf{7}$, but differing on the relative shifting of the molecules along the direction of propagation (Fig. 8a). Adjacent $1 \mathrm{D}$ rows are bridged by the $\mathrm{I}_{2}$ molecules via $\mathrm{S} \cdots \mathrm{I}$ XBs (see 
Table 1) supported by weak C-H $\cdots$ I interactions involving the methyl groups [C $\cdots$ I distances are 3.959(3) $\AA$ ] to form a corrugated $2 \mathrm{D}$ arrangement approximately parallel to the ac plane (Fig. 8b) which are then stacked along the $b$ direction (Fig. 8c), connected each other via a set of $\mathrm{C}-\mathrm{H} \cdots \mathrm{S}, \mathrm{C}-\mathrm{H} \cdots \mathrm{O}$ and $\mathrm{C}-\mathrm{H} \cdots \mathrm{I}$ weak interactions $[\mathrm{C} \cdots \mathrm{S}$ distances are 3.952(4), $\mathrm{C} \cdots \mathrm{O}$ distances are 3.399(4) and 3.553(4) $\AA$, C $\cdots$ I distances are 3.973(3) $\AA$, Table 2S $]^{\dagger}$.

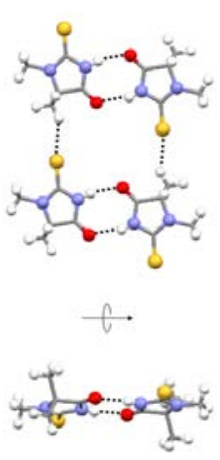

(a)

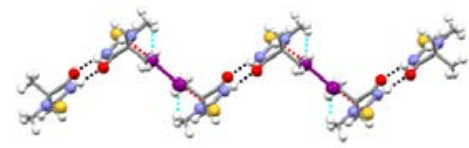

(b)

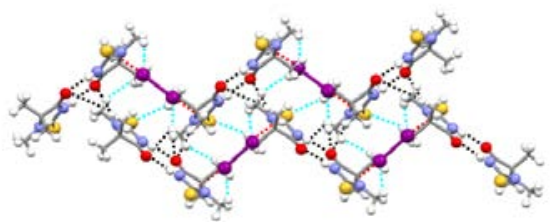

(c)
Fig. 8. Main molecular arrangements observed in 3. (a) 1D row of $\mathbf{m d t h}$ dimers viewed approximately along the [111] direction (top) and along the $a$ direction (bottom); (b) corrugated 2D arrangement of the CT adducts viewed along the $a$ direction; (c) portion of the packing of $\mathbf{3}$ viewed along the $a$ direction. $\mathrm{N}-\mathrm{H} \cdots \mathrm{O}$ and $\mathrm{C}-\mathrm{H} \cdots \mathrm{O}$ interactions are represented as black dashed lines, $\mathrm{S} \cdots \mathrm{XBs}$ as red dashed lines, $\mathrm{C}-\mathrm{H} \cdots \mathrm{S}$ and $\mathrm{C}-\mathrm{H} \cdots \mathrm{I}$ as cyan dashed lines.

Theoretical study. We have focused our theoretical study to analyse energetically the remarkable halogen bonding interactions (XBs) observed in the solid state architecture of complexes 1-7. As commented above the combination of XB and $\mathrm{HB}$ (hydrogen bonding) governs the crystal growth of the title compounds. In this theoretical study we have investigated $\mathrm{XBs}$ between $\mathrm{I}_{2} / \mathrm{IBr}$ and the heterocyclic chalcogenone donor in their geometric and energetic aspects. Moreover, we have analysed cooperativity effects, particularly the influence of HBs on the strength of the XBs using several computational tools. First of all, we have computed the molecular electrostatic potential (MEP) surface plots of the heterocyclic chalcogenone donors and their self-assembled $\mathrm{H}$ bonded dimers. The results are gathered in Fig. 9 and it can be observed that MEP value at the S/Se lone pair is similar in all compounds ranging from -31 to $-28 \mathrm{kcal} / \mathrm{mol}$. Interestingly, in the dimers, where two self-complementary HBs are formed, the MEP value at the lone pair becomes more negative, thus increasing the Lewis basicity of the chalcogen atom. Therefore the dimer formation likely enhances the strength of the XBs in the solid state. The MEP value at the $\mathrm{NH}$ group that does not participate in the formation of the self-assembled dimers (see Figs. 9a,c,d) slightly decreases upon formation of the dimer.

We have fully optimized the dihalogen adducts of chalcogenone donors both as monomers and also as H-bonded dimers at the RIMP2/def2-TZVP level of theory (see Table 3S for Cartesian coordinates of optimized structures, ESI) ${ }^{\dagger}$. The geometric and energetic results for compounds 1-3 are given in Fig. 10. It is worthy to emphasize that the optimized 1:1 complexes are similar to the motifs found in the crystal structures. The experimental and calculated distances differ because the crystal environment has not been considered in the calculations. However, it is very relevant that the binding modes of the fully relaxed complexes are almost identical to those found in the crystal structures since it indicates that these are strong binding motifs controlling the crystal growth. This notwithstanding, from the inspection of the energetic results summarized in Fig. 10, several issues arise. First, the binary adduct 1 (Fig. 10a) presents the largest donor/dihalogen binding energy ($12.1 \mathrm{kcal} / \mathrm{mol}$ ) and the shortest equilibrium $\mathrm{S} \cdots \mathrm{I}$ distance in line with the more positive MEP value calculated at the I atom $\sigma$-hole of $\mathrm{IBr}(15.7 \mathrm{kcal} / \mathrm{mol})$ as compared to the value calculated in the case of $\mathrm{I}_{2}(14.4 \mathrm{kcal} / \mathrm{mol})$. Second, the binding modes of mdth with $\mathrm{I}_{2}$ observed in the solid state of compounds 2 and $\mathbf{3}$ (see Figs 10b,c) exhibit almost identical interaction energies.
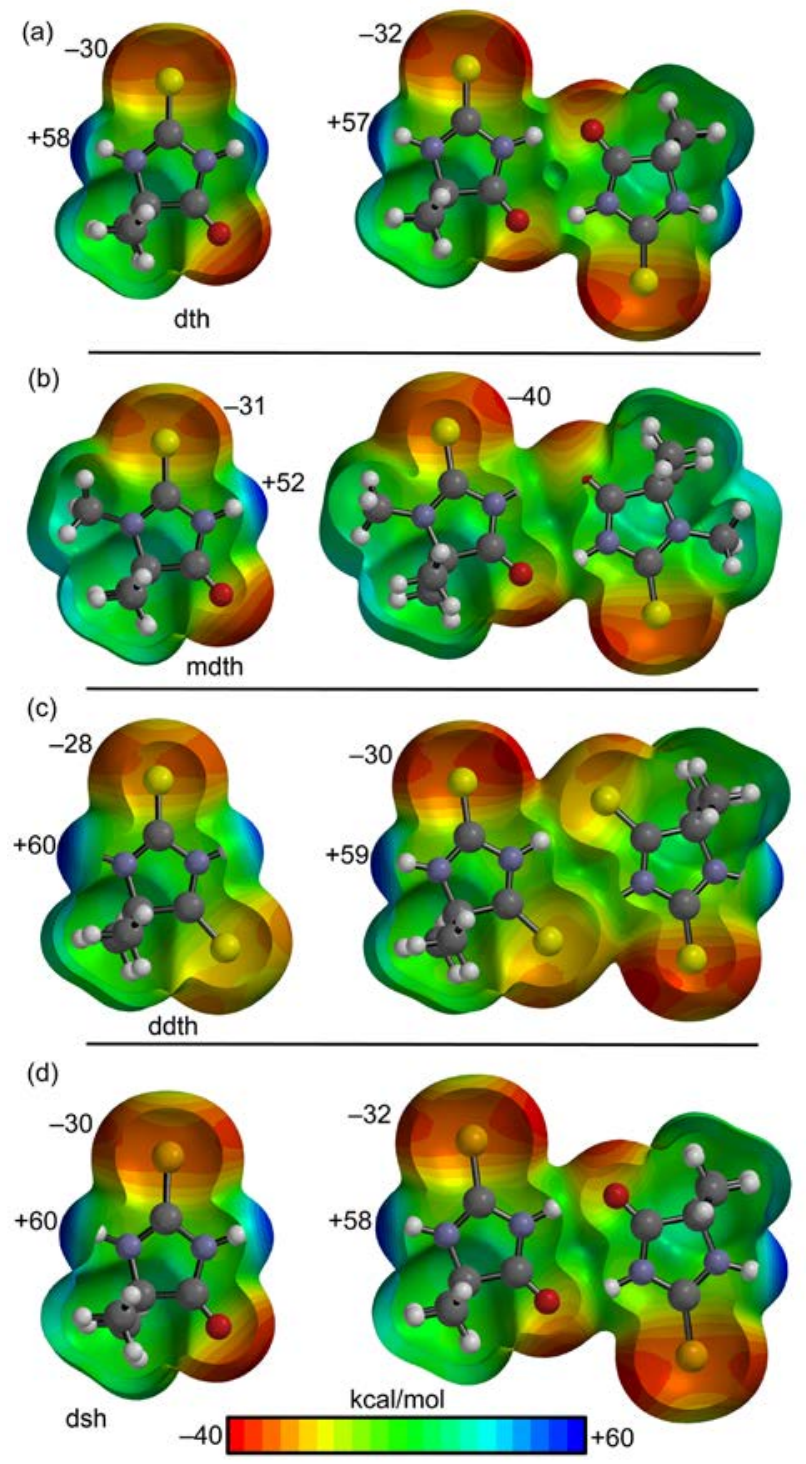

Figure 9. MEP surface plots of the heterocyclic chalcogenone donors and their self-assembled $\mathrm{H}$-bonded dimers. The MEP values at selected points of the surface are indicated.

Third, in all cases the donor/dihalogen interaction energy becomes more favorable if the self-assembled donor dimer is 
considered, thus revealing a reinforcement of the XB by the HBs responsible of the dimers formation (these interaction energies have been computed considering the H-bonded dimer previously formed, thus only the interaction with the dihalogen is evaluated). This effect is also revealed by $\mathrm{I} \cdots \mathrm{S}$ equilibrium distances calculated in all cases to be shorter in the ternary assemblies than in the binary adducts.

(a)

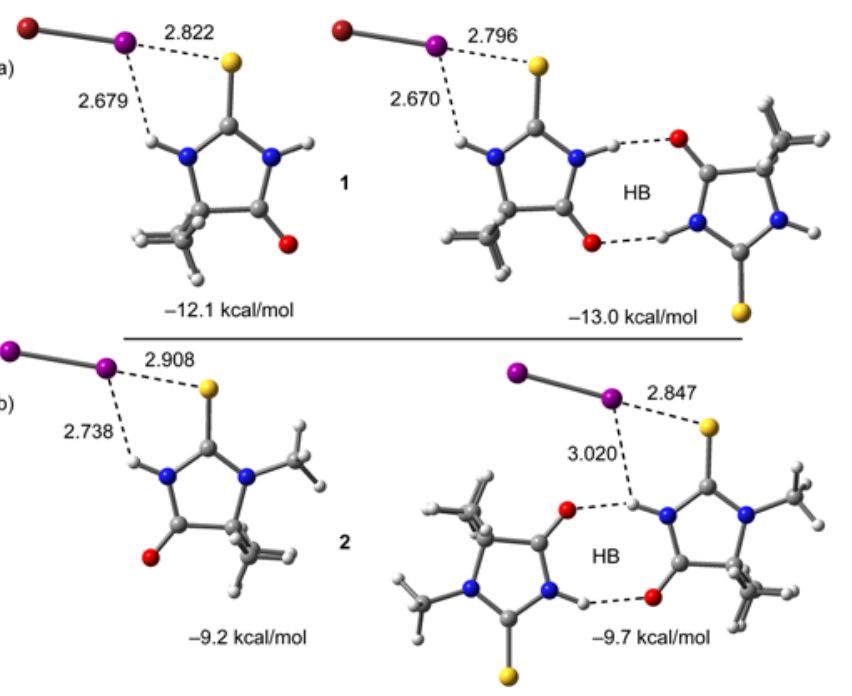

(c)
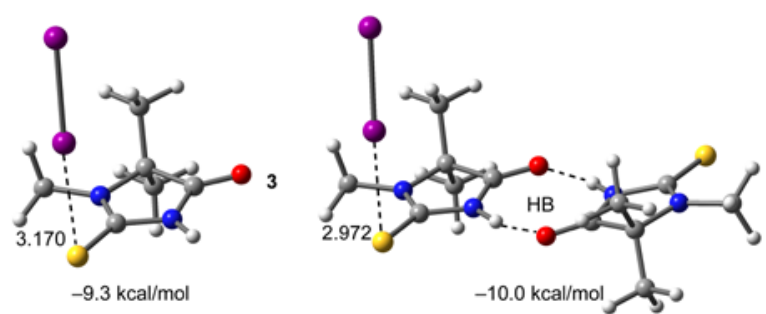

Figure 10. RI-MP2/def2-TZVP optimized dihalogen adducts for compounds 1-3 equilibrium distances $(\AA ̊)$ and interaction energies (BSSE corrected) are also given.

For comparison purposes, we have carried out a similar study for compounds 4-7 and the results are given in Figure 11. Interestingly, in all cases the XBs strengthen upon formation of the self-assembled $\mathrm{H}$-bonded dimers, indicating a favorable cooperativity effect. Moreover, the Se'-I interaction (Fig. 11d) is more favorable than the $\mathrm{S} \cdots \mathrm{I}$ one (Fig. 11c) in agreement with the MEP analysis discussed above, since the MEP value at the Lone Pair (LP) of Se is more negative than that at the LP of S. Finally, the energetic analysis of the KUWDIP (5) structure (Fig. 11b) shows that both the $\mathrm{S} \cdots \mathrm{I}$ and $\mathrm{N}-\mathrm{H} \cdots \mathrm{I}$ interactions in the 1:1 adduct (Fig. 11a left) are modestly weakened (longer distances; 0.14 and $0.15 \AA$, respectively) upon the formation of the additional $\mathrm{S} \cdots \mathrm{I}$ interaction involving the second sulfur atom of the ring (see Fig 11b). Consequently, the interaction energy becomes slightly less favorable (by $0.7 \mathrm{kcal} / \mathrm{mol}$ ). In short, the formation of self-assembled H-bonded dimers (compounds 1-4, 6 and 7) tends to slightly strengthen the $\mathrm{XB}$ interaction and, conversely, the formation of additional $\mathrm{XB}+\mathrm{HB}$ interactions in compound 5 causes an opposite, albeit minimal, anti- cooperativity effect. We have used the Bader's theory of atoms in molecules (AIM) that provides an unambiguous definition of chemical bonding (both covalent and noncovalent) to further characterize the XBs described above. In Fig. 12 we have represented the AIM distribution of bond critical points (BCPs) and bond paths for the 1:1 adducts and the corresponding adducts of donor dimers (ternary assemblies) of compounds $\mathbf{1}$, 3 and KUWDIP, 5, (as representative examples of compounds 1-7, see Tables 4S-11S for calculated AIM parameters, ESI) ${ }^{\dagger}$. In the $1: 1$ adduct 1 (see Fig. 12a), the $\mathrm{XB}$ is characterized by the presence of a BCP (red sphere) connecting the I atom to the $\mathrm{S}$ atom. Moreover, the ancillary $\mathrm{N}-\mathrm{H} \cdots \mathrm{I}$ is also characterized by a BCP connecting the $\mathrm{H}$ to the $\mathrm{I}$ atom. As a consequence of the formation of a supramolecular ring due to the halogen/hydrogen bonding interaction, the formation of a ring $\mathrm{CP}$ (yellow sphere) is also observed. In the ternary assembly, the interaction of the dth dimer with $\mathrm{IBr}$ is characterized by the same distribution of critical points.

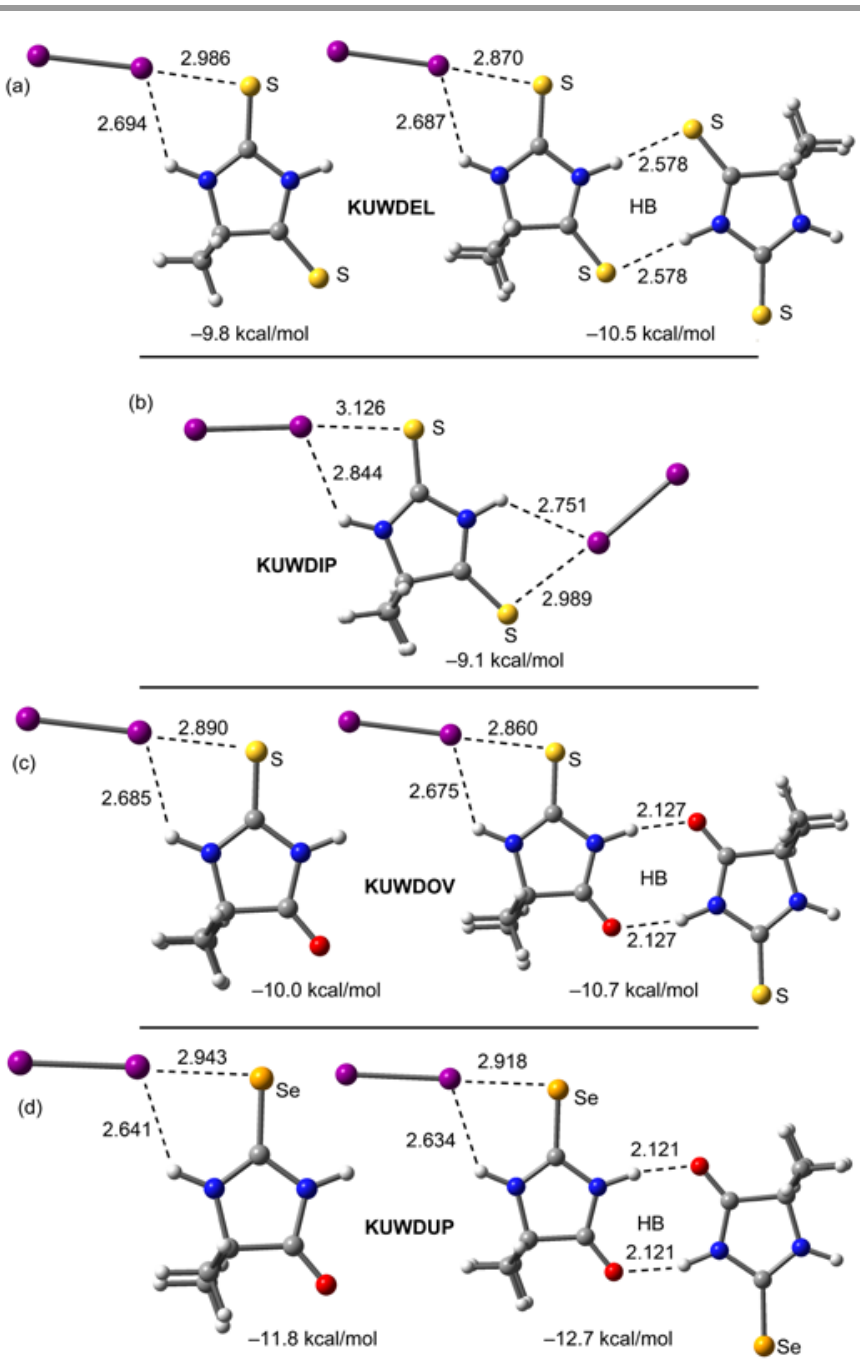

Fig. 11. RI-MP2/def2-TZVP optimized adducts for compounds KUWDEL (4), KUWDIP (5), KUWDOV (6) and KUWDUB (7), equilibrium distances ( $\AA$ ) and interaction energies (BSSE corrected) are also given. 
It has been demonstrated that the value of the charge density at the BCP is a convenient indicator of the interaction strength. It can be observed that the value of $\rho(r)$ at both BCPs that characterize the $\mathrm{XBs} / \mathrm{HBs}$ increases in the ternary assembly with respect to the binary adduct, thus confirming the reinforcement of both $\mathrm{XB}$ and $\mathrm{HB}$ interactions (synergetic effect).

In compound 3 (Fig. 12b), BCPs are calculated for both the XB interactions between $\mathrm{I}_{2}$ and the mdth donor, and the two ancillary $\mathrm{C}-\mathrm{H} \cdots \mathrm{I}$ interactions which also contribute to the stabilization of the binding mode of $\mathrm{I}_{2}$ perpendicular to the ring plane. In the corresponding ternary assembly, the $\mathrm{XB}$ is significantly reinforced with respect to the binary adduct as indicated by the increase in the value of $\rho(r)$ at the $\mathrm{BCP}$, whilst the two ancillary $\mathrm{C}-\mathrm{H} \cdots \mathrm{I}$ interactions basically remain unaltered (slight variation of $\rho(\mathrm{r})$ ).

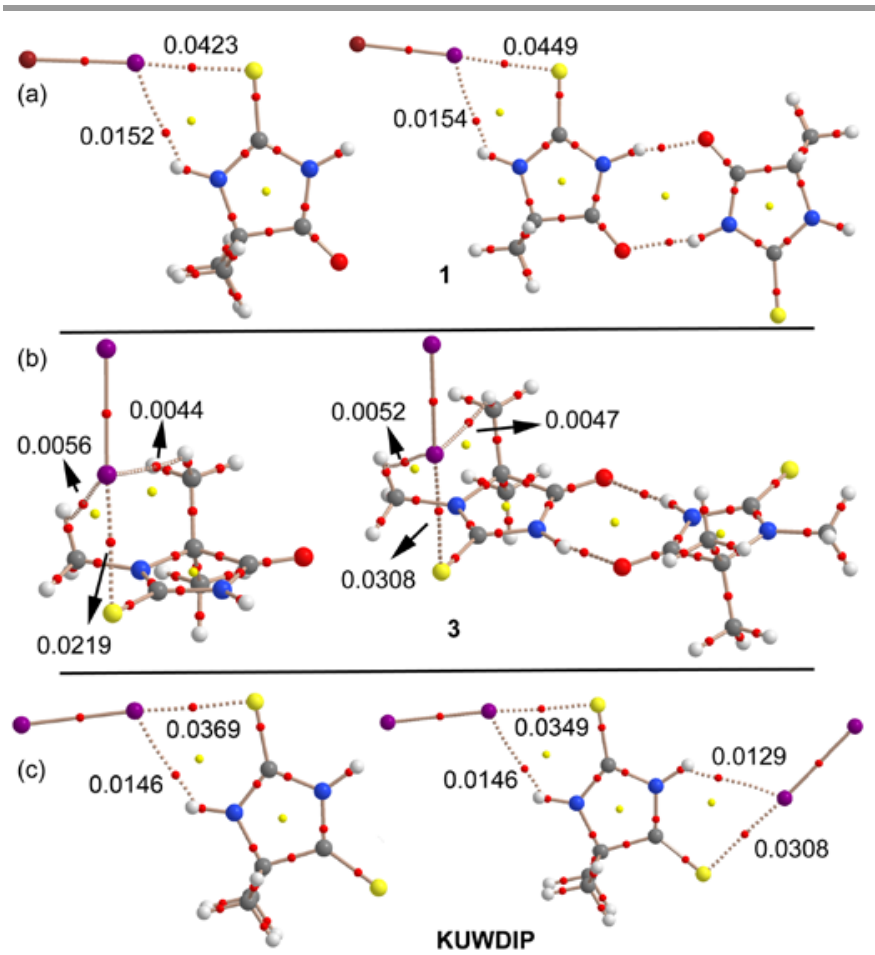

Fig. 12. Distribution of critical points and bond paths in the adducts considered for 1, 3 and KUWDIP (5). Bond and ring critical points are represented by red and yellow spheres, respectively. The bond paths connecting bond critical points are also represented. The value of the density at the bond critical points in a.u. is also indicated.

Finally, the distribution of BCPs in the 1:2 $\mathrm{I}_{2}$ adduct of ddth, 5 (Fig. 12c), reveals that both $\mathrm{XB}$ interactions are characterized by a BCP and a bond path connecting the $\mathrm{S}$ and the I atoms. The ancillary $\mathrm{HB}$ interactions are also characterized by the presence of a BCP and a bond path inter-connecting the $\mathrm{H}$ and I atoms. Furthermore, ring CPs are also generated as a consequence of the formation of supramolecular rings (yellow sphere in Fig. 12c). Moreover, it can be observed that the $\rho(\mathrm{r})$ value at the BCP that characterizes the XB interaction decreases in the ternary assembly (Table $11 S)^{\dagger}$ as compared to the binary adduct (Table $10 \mathrm{~S})^{\dagger}$, indicating a weakening of the interaction, in agreement with the longer S $\cdots I$ distance observed in the ternary assembly (see Fig. 11b ) and the slight anticooperativity effect commented above.
It should be mentioned that although the Laplacian of $\rho(r)$ at the $\mathrm{S}-\mathrm{I}$ BCP is positive in all complexes gathered in Fig. 12, the local electronic energy density, $\mathrm{H}$, is negative, thus indicating that the $\mathrm{XB}$ interaction shows a significant covalent contribution and, therefore, a lowering of the potential energy associated with the concentration of charge between the nuclei. $^{12 \mathrm{e}}$

We have also analyzed theoretically the formation of $\mathrm{N}-\mathrm{H} \cdots \mathrm{I}-$ $\mathrm{I} \cdots$ Se arrangements in 7 following the insertion of $\mathrm{I}_{2}$ molecules in the $\mathrm{N}-\mathrm{H} \cdots$ Se HBs holding dimers of dsh units in the crystal structure (FILXIH) of the donor molecule (Fig. 3).

The insertion of two $\mathrm{I}_{2}$ molecules in a self-assembled $\mathrm{N}-\mathrm{H} \cdots$ Se $\mathrm{H}-$ bonded dimer of dsh units in FILXIH to form the $\mathrm{N}-\mathrm{H} \cdots \mathrm{I}-\mathrm{I} \cdots \mathrm{Se}$ supramolecular assemblies observed in $\mathbf{7}$ is energetically favourable (-27.6 kcal/mol) (Fig. 13). Moreover, the formation of the I-I $\cdots$ Se bond drastically affects the MEP value at the $\sigma$-hole of $I_{2}$ (see Fig. 13b), which changes from positive to negative (see Fig. 13c) upon the formation of the $\mathrm{I} \cdots$ Se halogen bond, thus favouring the $\mathrm{N}-\mathrm{H} \cdots \mathrm{I}$ interaction.

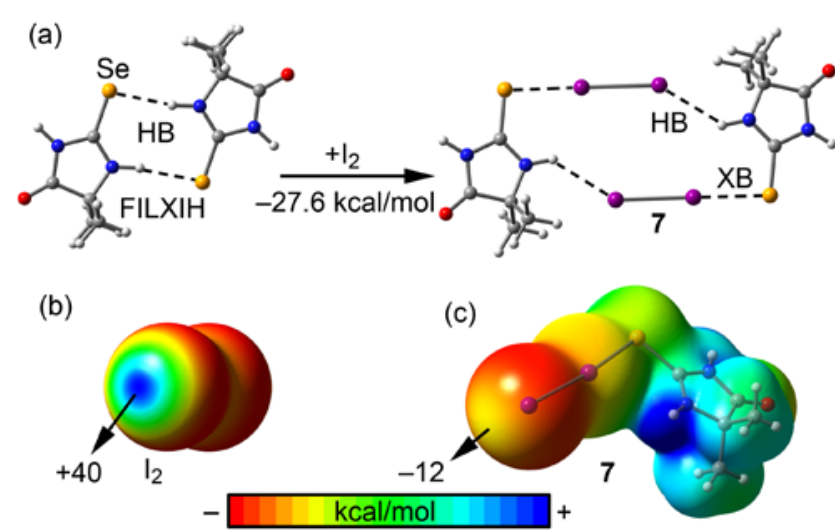

Fig. 13. (a) Evaluation of the $I_{2}$ insertion into an $H$-bonded self-assembled dimer in FILXIH (geometries and energies at MP2/def2-TZVP level of theory). (b) MEP surface plot of $I_{2}$. (c) MEP surface plot of the molecular unit in 7. The MEP values at selected points of the surface are indicated in the case of $I_{2}$ and the molecular unit in 7.

\section{Conclusions}

In this manuscript we report the synthesis and X-ray characterization of three new molecular adducts with dihalogens (1-3), based on 5,5-dimethyl-2-thiohydantoin (dth) and 1,5,5-trimethyl-2-thiohydantoin (mdth). These three new structures were compared with those of similar dihalogen CT adducts reported before. We also compared their energetic and geometric features by means of $a b$ initio calculations and analyzed cooperativity effects, particularly the influence of HB interactions on the strength of the XB using several computational tools.

The results confirms the complexity and unpredictability of supramolecular architectures in dihalogen CT adducts of chalcogen donor molecules evidencing that small differences at molecular level of the donor molecules can significantly influence the geometry of the $\mathrm{E}-\mathrm{X}-\mathrm{Y}$ XBs. However, some common features can be identified. Despite the energy 
calculated for the "parallel" and "orthogonal" conformers (compare compounds 1, 2, 4-7 with compound 3) show similar values, the majority of the dihalogen CT adducts shows a preference for the former conformation. Nevertheless changes in the stoichiometric ratio of dihalogen CT adducts can also have dramatic influence on the geometry of the XBs interactions and, consequently, on the resulting supramolecular architectures.

The crystal packing analysis and $a b$ initio calculations show the existence of cooperativity effects between the $\mathrm{HB}$ and $\mathrm{XB}$ interactions. In particular, in most of the cases the formation of $\mathrm{N}-\mathrm{H} \cdots \mathrm{E}$ centrosymmetric donor dimers (with $\mathrm{E}=\mathrm{O}, \mathrm{S}$, Se) enhances the strength of the $\mathrm{XB}$ interaction, indicating a favorable cooperativity effect, which is at the base of the supramolecular architectures formed. We also observed that in some cases the pair of cooperative $\mathrm{N}-\mathrm{H} \cdots \mathrm{X}-\mathrm{Y} \cdots \mathrm{E} \mathrm{HB}$ and $\mathrm{XB}$ interactions can mimic a simpler $\mathrm{N}-\mathrm{H} \cdots \mathrm{E}$ HB, promoting analogous supramolecular architectures in the solid state structures of dihalogen CT adducts and the corresponding donor molecules (see Fig. 3).

\section{Experimental}

\section{Materials and instruments.}

Reagents and solvents of reagent grade purity were used as received from Aldrich. The compounds dth and mdth were prepared as described previously. ${ }^{15}$ The reactivity of both dth and mdth towards $\mathrm{I}_{2}$ and $\mathrm{IBr}$ was tested in $\mathrm{CH}_{2} \mathrm{Cl}_{2}$ (the use of more polar solvents can favor the formation of products different from CT adducts, which are out the aim of the present work $)^{9,11}$ using both a 1:1 and a 1:2 donor-to-dihalogen molar ratio. Only in the case of 1-3 solid products were isolated (see below). In the case of $\mathbf{1}$, crystal growth was performed at -10 ${ }^{\circ} \mathrm{C}$ to favor the formation of bigger crystals. In the case of $\mathbf{2}$ and 3, no significant effects were observed on the size of the crystals formed by performing the crystallization at a low temperature.

FT-Raman spectra (resolution $\pm 4 \mathrm{~cm}^{-1}$ ) were recorded on a Bruker RFS100 FTR spectrometer fitted with an indiumgallium arsenide detector (room temp) and operating with an excitation frequency of $1064 \mathrm{~nm}$ (Nd:YAG laser). The power level of the laser was tuned between 20-40 mW. No sample decomposition was detected during the experiments.

\section{[(dth)IBr] (1).}

5,5-dimethyl-2-thiohydantoin (100 mg, $0.694 \mathrm{mmol}$ ) in $\mathrm{CH}_{2} \mathrm{Cl}_{2}$ $(10 \mathrm{~mL})$ and $\mathrm{IBr}(158 \mathrm{mg}, 0.76 \mathrm{mmol})$ in $\mathrm{CH}_{2} \mathrm{Cl}_{2}(10 \mathrm{~mL})$ were reacted at $10{ }^{\circ} \mathrm{C}$ for $15 \mathrm{~min}$, then the filtered solution was allowed to stand at $-10{ }^{\circ} \mathrm{C}$ for $7 \mathrm{~d}$. The product was obtained as dark-orange crystals, washed with a mixture $\mathrm{CH}_{2} \mathrm{Cl}_{2} / n$-hexane $1: 10 \mathrm{v} / \mathrm{v}(10 \mathrm{~mL})\left(10 \mathrm{~mL}, 0^{\circ} \mathrm{C}\right)$ and stored under nitrogen atmosphere. Yield: $207 \mathrm{mg}, \quad 85 \% . \quad \mathrm{C}_{5} \mathrm{H}_{8} \mathrm{BrIN}_{2} \mathrm{OS}$ (350.84 g/mol): calcd. C 17.10, H 2.30, N 7.98, S 9.11); found C 17.0, H 2.3, N 8.0, S 9.3). FT-Raman: $v=178.5 \mathrm{~s}[v(\mathrm{I}-\mathrm{Br})] \mathrm{cm}^{-1}$.

[(mdth) $\left.\mathbf{I}_{2}\right]$ (2). 1,5,5-trimethyl-2-thiohydantoin (100 $\mathrm{mg}, 0.633 \mathrm{mmol})$ in $\mathrm{CH}_{2} \mathrm{Cl}_{2}(15 \mathrm{~mL})$ and $\mathrm{I}_{2}(161 \mathrm{mg}, 0.633 \mathrm{mmol})$ in $\mathrm{CH}_{2} \mathrm{Cl}_{2}$ (35 $\mathrm{mL}$ ) were reacted at $20^{\circ} \mathrm{C}$ for $15 \mathrm{~min}$, then the filtered solution was allowed to slowly concentrate to air. The product was obtained as dark-red crystals, washed with a mixture $\mathrm{CH}_{2} \mathrm{Cl}_{2} / n$ hexane $1: 9 \mathrm{v} / \mathrm{v}(10 \mathrm{~mL})$ and stored under nitrogen atmosphere. Yield: $237.1 \mathrm{mg}, 91 \%$. $\mathrm{C}_{6} \mathrm{H}_{10} \mathrm{I}_{2} \mathrm{~N}_{2} \mathrm{OS}$ (411.86 g/mol): C 17.48, H 2.45, N 6.80, S 7.76); found C 17.3, H 2.4, N 6.7, S 7.6). FTRaman: $v=152.3 \mathrm{~s}[\mathrm{v}(\mathrm{I}-\mathrm{I})] \mathrm{cm}^{-1}$.

\section{[(mdth) $\left.)_{2} \mathbf{I}_{2}\right]$ (3).}

1,5,5-trimethyl-2-thiohydantoin (100 $\mathrm{mg}, 0.633 \mathrm{mmol})$ in $\mathrm{CH}_{2} \mathrm{Cl}_{2}(15 \mathrm{~mL})$ and $\mathrm{I}_{2}(81 \mathrm{mg}, 0.316 \mathrm{mmol})$ in $\mathrm{CH}_{2} \mathrm{Cl}_{2}(25$ $\mathrm{mL}$ ) were reacted at $20^{\circ} \mathrm{C}$ for $15 \mathrm{~min}$, then the filtered solution was allowed to slowly concentrate to air. The product was obtained as dark-red crystals, washed with a mixture $\mathrm{CH}_{2} \mathrm{Cl}_{2} / n$ hexane $1: 9 \mathrm{v} / \mathrm{v}(10 \mathrm{~mL})$ and stored under nitrogen atmosphere. Yield: $306.6 \mathrm{mg}, 85 \%$. $\mathrm{C}_{12} \mathrm{H}_{20} \mathrm{I}_{2} \mathrm{~N}_{4} \mathrm{O}_{2} \mathrm{~S}_{2}$ (569.91 g/mol): C 25.27, H 3.54, N 9.83, S 11.22, found C 25.4, H 3.6, N 9.9, S 11.4). FT-Raman: $v=172.7 \mathrm{~s}[v(\mathrm{I}-\mathrm{I})] \mathrm{cm}^{-1}$.

\section{X-ray crystallography}

The single-crystal data collection for 1-3 were performed at room temperature on an Enraf-Nonius CAD4 diffractometer using graphite-monochromatized Mo-K $\alpha$ radiation $(\lambda=0.71073$ $\AA)$, and $\omega$ scans. The crystals used were coated with cyanoacrylate glue in order to prevent decomposition due to loss of $\mathrm{I}_{2}$ or $\mathrm{IBr}$ during data collection. After standard data collection procedures, the datasets were corrected for Lorentz polarization effects and for absorption by using multi-scan semiempirical methods ( $\psi$-scans). The structures were solved by direct methods using SHELXS-97 and refined by full matrix least squares on $F^{2}$ using SHELXL-97. ${ }^{23}$ All non-hydrogen atoms were refined anisotropically, all hydrogen atoms were placed in idealized positions and refined using a riding model. X-ray crystallographic data in CIF format have been deposited with the Cambridge Crystallographic Data Centre, CCDC no. 153651315366515 .

\section{Theoretical methods.}

The geometries of all complexes were optimized at the RIMP2/def2-TZVP level of theory by means of the Turbomole 7.0 software. $^{24}$ It has been previously demonstrated that this level of theory is adequate for studying halogen bonding interactions since it gives energies comparable to those using the CCDC(T) method. ${ }^{25}$ Moreover, it has been also shown that it is of higher quality than any pure or hybrid DFT-D3 method. ${ }^{25}$ For the iodine atom we have used the def2-TZVPP basis set than includes two sets of polarization functions. Moreover, both the def2-TZVP and def2-TZVPP basis sets include for $5 p$ and $6 p$ block elements effective core potential of 46 electrons (ECP-46). ${ }^{26}$ The nature of all the energy minima were verified by a vibrational analysis. The interaction energies were calculated with correction for the basis set superposition error (BSSE) by using the Boys-Bernardi counterpoise technique. $^{27}$ No symmetry constrains were imposed in the optimizations of the complexes. The Bader's "Atoms in 
molecules" theory has been used to study the halogen bonding interactions discussed herein by means of the AIMall calculation package. $^{28}$ The MEP surface analysis was performed at the same level of theory and the MEPS figures have been generated using GaussView. ${ }^{29}$

\section{Acknowledgements}

We would like to thank the Università degli Studi di Cagliari and Fondazione di Sardegna for financial support. A.B. and A.F. thank the MINECO of Spain (project CTQ2014-57393C2-1-P, FEDER funds) for financial support. We thank the CTI (UIB) for computational facilities.

\section{Notes and references}

${ }^{a}$ Dipartimento di Scienze Chimiche e Geologiche, Università degli Studi di Cagliari, S.S. 554 Bivio per Sestu, 09042 Monserrato (CA), Italy.

${ }^{b}$ Departament de Quimica, Universitat de les Illes Balears, Crta de Valldemossa Km 7.5, 07122, Palma de Mallorca (Baleares), Spain.

c Dipartimento di Chimica, Università degli Studi di Milano, via Golgi 19, 20133 Milano, Italy.

†Electronic ESI (ESI) available: Additional information as noted in the text including: Cartesian coordinates of the optimised structures (Table 3S) and AIM parameters at Bond Critical Points (Tables 4S-11S). See DOI: 10.1039/b000000x/

(a) L. C. Gilday, S. W. Robinson, T.A. Barendt, M. J. Langton B. R. Mullaney and P. D. Beer, Chem.Rev. 2015, 115, 7118-7195; (b) P. Metrangolo, F. Meyer, T. Pilati, G. Resnati, G. Terraneo, Angew.Chem. Int. ed. 2008, 47, 61146127; (c) C. B. Aakeröy, J. Desper, M. Fasulo, I. Hussain, B. Levin and N. Schultheiss, CrystEngComm, 2008, 10, 18161821; (d) C. B. Aakeröy, M. Fasulo, N. Schultheiss, J. Desper, and C. Moore,J. Am. Chem. Soc., 2007, 129, 1377213773; (e) C. B. Aakeröy, T. K. Wijethunga, J. Desper, and M. Đaković, Cryst. Growth Des., 2015, 15, 3853-3861.

2. (a) G. R. Desiraju, Crystal Engineering: The design of Organic Solids, Elsevier, 1989, Amsterdam; (b) G. Desiraju, Angew. Chem. Int. Ed. 2007, 46, 8342-8356; (c) C. B. Aakeröy, N. R. Champness and C. Janiak, CrystEngComm, 2010, 12, 22-43.

3. (a) C. B. Aakeroy, A. M. Beatty, and K. R. Lorimer Struct. Chem., 1999, 10, 229-242 (b) M.; Olejniczak, A.; Katrusiak, A. CrystEngComm., 2012, 14, 6374-6376. (c) T.J. Mooibroek, P. Gamez, CrystEngComm 2013, 15 4565-4570; (d) N. Nagels, Y. Geboes, B. Pinter, F. De Proft, W.A. Herrebout, Chem. Eur. J. 2014, 20, 8433-8443.

4. (a) L. Koskinen, P. Hirva, A. Hasu, S. Jääskeläinen, J. Koivistoinen, M. Pettersson and M. Haukka CrystEngComm, 2015, 17, 2718-2727; (b) C. B. Aakeröy, N. Schultheiss, J. Desper and C. Moore, CrystEngComm, 2007, 9, 421-426; (c) G. Berger, K. Robeyns, J. Soubhye, R. Wintjens and F. Meyer CrystEngComm, 2016, 18, 683-690; (d) G. Mínguez Espallargas, F. Zordan, L. Arroyo Marín, H. Adams, K. Shankland, J. van de Streek and L. Brammer, Chem. Eur. J., 2009, 15, 7554-7568; (e) A. Bauzá, D. Quiñonero, A. Frontera, P.M. Deyà, Phys. Chem. Chem. Phys., 2011, 13, 20371-20379, (f) M.C. Aragoni, M. Arca, S.J. Coles, F.A. Devillanova, M.B. Hurtshouse, S.L. Coles (née Huth), F. Isaia, V. Lippolis, A. Mancini, CrystEngComm, 2011, 13, 6319-6322.

5. C. B. Aakeröy, S.Forbes and J. Desper, CrystEngComm, 2014, 16, 5870-5877.
C. B. Aakeroy., C. L. Spartz, S. Dembowski, S. Dwyre, and J. Desper,. IUCrJ, 2015, 2, 498-510.

(a) T. Gelbrich and M. B. Hursthouse CrystEngComm, 2006, 8, 448-460; (b) M. B. Hursthouse, R. Montis, L. Niitsoo, J. Sarson, T. L. Threlfall, A. M. Asiri, S. A. Khan, A. Y. Obaid and L. M. Al-Harbi, CrystEngComm, 2014, 16, 2205-2219; (c) V. V. Klepov, A. V. Vologzhanina, E. V. Alekseev, D. V. Pushkin, L. B. Serezhkina, O. A. Serqeeva, A. V. Knyazev and V. N. Serezhkin, CrystEngComm, 2016, 18, 1723-1731; (e) Y.-X. Li, X.-F. Yang, J.-L. Miao, Z.-W Zhang and G.-X. Sun, CrystEngComm, 2016, 18, 2098-2104; (f) C. A. Figueira , P. S. Lopes, C. S. B. Gomes, L. F. Veiros and P. T. Gomes, CrystEngComm, 2015, 17, 6406-6419.

8. (a) T. Gelbrich, M. B. Hursthouse, CrystEngComm, 2005, 7, 324-336; (b) S. L. Childs, P. A. Wood, N. RodriguezHornedo, L. S. Reddy and K. I. Hardcastle, Cryst. Growth Des. 2009, 9, 1869-1888; (c) M. B. Hursthouse, R. Montis and G. J. Tizzard CrystEngComm, 2011, 13, 3390-3401; (d) R. Montis, M. B. Hursthouse, CrystEngComm, 2012, 14, 7466-7478; (e) R. Montis, M. B. Hursthouse, CrystEngComm, 2012,14, 5242-5254.

9. (a) M. Arca, F. Demartin, F.A. Devillanova, A. Garau, F. Isaia, V. Lippolis, G. Verani, Trends in Inorg. Chem., 1999, 6, 1-18; (b) P.D. Boyle, S.M. Godfrey, Coord. Chem. Rev., 2001, 223, 265-299 (c) A. Garau, F. Isaia, V. Lippolis, A. Mancini, G. Verani, Bioinorg. Chem. Appl. 2006, 1, 1-12.

10. (a) F. Isaia, M. C. Aragoni, M. Arca, F. Demartin, F. A. Devillanova, G. Floris, A. Garau, M. B. Hursthouse, V. Lippolis, R. Medda, F. Oppo and G. Verani, J. Med. Chem., 2008, 5, 4050-4053; (b) Raby, C.; Lagorce, J. F.; JambutAbsil, A. C.; Buxeraud, J.; Catanzano, G. Endocrinology, 1990, 126, 1683-1691; (c) G. Roy, K. P. Bhabak, and G. Mugesh Cryst.GrowthDes. 2011， 11，2279-2286; (d) Vengurlekar S., Sharma R., Trivedi P. Letters in Drug Design and Discovery 2012, 9, 549-555; (e) Mahajan D.H., Chikhalia K.H., Pannecouque C., De Clercq E. Pharmaceutical Chemistry Journal, 2012, 46, 165-170; (f) Mohammad M. Ghanbari, Gholam H. Mahdavinia, Javad Safari, Hossein Naeimi, and Mehdi Zare Synth Comm, 2011, 41, 2414-2420; (g) Asha D. Jangale, Yogesh B. Wagh, Yogesh A. Tayade, and Dipak S. Dalal, Synth.Comm., 2015, 45, 1876-1886; (h) H. Tavakol, T. Hadadi, H. Roohi, J. of Struct. Chem., 2012, 53, 649-658; (i) M. C. Aragoni, M. Arca, F. Demartin, F. A. Devillanova, A. Garau, F. Isaia,V. Lippolis, and G. Verani, J. Am. Chem. Soc. 2002, 124, 45384539.

11. (a) M.C. Aragoni, M. Arca, F. Demartin, F.A. Devillanova, A. Garau, F. Isaia, F. Lelj, V. Lippolis, G. Verani, Chem. Eur. J., 2001, 7, 3122-3133; (b) E.J. Juárez-Pérez, M.C. Aragoni, M. Arca, A.J. Blake, F.A. Devillanova, A. Garau, F. Isaia, V. Lippolis, R. Núñez, A. Pintus, C. Wilson, Chem. Eur. J., 2011, 17, 11497-11514.

12. (a) M.C. Aragoni, M. Arca, F. A. Devillanova, F. Isaia and V. Lippolis, Cryst. Growth Des., 2012, 12, 2769-2779; (b) G. Ciancaleoni, M. Arca, G.F. Caramori, G. Frenking, F.S.S. Schneider, V. Lippolis, Eur. J. Inorg. Chem., 2016, 23, 38043812; (c) C. Wang, D. Danovich, Y. Mo, S. Shaik, J. Chem. Theory Comput., 2014, 10, 3726-3737; (d) L.P. Wolters, P. Schyman, M.J. Pavan, W.L. Jorgensen, F.M. Bichelhaupt, S. Kozuch, WIREs Comput. Mol. Sci., 2014, 4, 523-540. (e) E.J. Juárez-Pérez, M.C. Aragoni, M. Arca, A.J. Blake, F.A. Devillaanova, A. Garau, F. Isaia, V. Lippolis, R. Nuñez, A. Pintus, C. Wilson, Chem. Eur. J., 2011, 17, 11497-11514.

13. (a) W. T. Pennington, T. W. Hanks, H. D. Arman, Struct. Bonding 2008, 126, 65-104; (b) V. Lippolis, F. Isaia in Handbook of Chalcogen Chemistry: New Perspectives in Sulfur, Selenium and Tellurium ( $2^{\text {nd }}$ Edition $), \quad$ F.A. Devillanova, W.-W. du Mont (Ed.s), RSC Publishing, 2013, Part 1, Chapter 8.2, 448-472; (c) M. Arca, F. Demartin, F.A. Devillanova, A. Garau, F. Isaia, V. Lippolis, G. Verani, J. Chem. Soc., dalton Trans., 1999, 3069-3073; (d) W.-W. du Mont, M. Bätcher, C. Daniliuc, F.A. Devillanova, C. 
Druckenbrodt, J, Jeske, P.G. Jones, V. Lippolis, R. Futhe, E. Seppälä, Eur. J. Inorg. Chem., 2008, 29, 4562-4577.

14. W.-W. du Mont, C.G. Hrib, Supramolecular Structures Based on Chalcogen-Halogen Secondary Bonds, in Handbook of Chalcogen Chemistry: New Perspectives in Sulfur, Selenium and Tellurium, F.A. Devillanova, W.-W. du Mont Eds, $2^{\text {nd }}$ edition Vol 2, pp 273-316, RSC Publishing, 2013, ISBN: 978-1-84973-624-4.

15. (a) F. Cristiani, F. Demartin, F.A. Devillanova, F. Isaia, G. Saba, G. Verani, J. Chem. Soc., Dalton Trans., 1992, 35533560; F. Cristiani, F.A. Devillanova, A. Diaz, F. Isaia, G. Verani, Heteroatom Chem., 1990, 5, 363-365.

16. I. J. Bruno, J. C. Cole, P. R. Edgington, M. Kessler, C. F. Macrae, P. McCabe, J. Pearson and R. Taylor, Acta Cryst., Sect. B: Struct. Sci., 2002, 58, 389-397.

17. A.J. Blake, F.A. Devillanova, A. garau, L.M. Gilby, R.O. Gould, F. Isaia, V. Lippolis, S. Parsons, C. Radek, M. Schröder, J. Chem. Soc., Dalton Trans., 1998, 2037-2046.

18. A. Bondi, J.Phis.Chem, 1964, 68, 441-451.

19. (a) C. Ouvrard, J.-Y. Le Questel, M. Berthelot and C. Laurence, Acta Cryst., 2003, B59, 512-526; (b) A. Mancini, L. Pala, M. C. Aragoni, M. Arca, F. A. Devillanova, M. B. Hursthouse, M. E. Light, P. J. Skabara and N. Bricklebank, Eur.J. Inorg. Chem.,2012, 2373-2380; (c) C. Laurence, M. J. El Ghomari, J.-Y. Le Questel, M. Berthelot, and R. Mokhlisse, J. Chem. Soc. Perkin Trans. 1998, 2, 1545-155.

$20 . \quad$ T. Ogawa, H. Okumura, M. Honda, M. Suda, S. Fujinami, A. Kuwae, K. Hanai, K.-K. Kunimoto, X-ray Struct. Anal. Online, 2009, 25, 91-91.

21 F.A. Devillanova, F. Isaia, G. Verani, L.P. Battaglia, A.B. Corradi, J. Chem. Res., 1987, 192, 1617-1638.

22. M.E.Sulbaran, G.E.Delgado, A.J.Mora, A.Bahsas, H.N.de Armas, N.Blaton, Acta Cryst. Sect. C, 2007, 63, o543-0545.

23. G.M. Sheldrick, Acta Cryst., 2008, A64, 112-122.

24. R. Ahlrichs, M. Bär, M. Hacer, H. Horn and C. Kömel, Chem. Phys. Lett., 1989, 162, 165-169.

25. A. Bauzá, I. Alkorta, A. Frontera and J. Elguero, J. Chem. Theory Comput., 2013, 9, 5201-5210.

26. F. Weigend and R. Ahlrichs; Phys. Chem. Chem. Phys. 2005, 7, 3297-3305.

27. $\quad$ S. B. Boys, F. Bernardi, Mol. Phys., 1970, 19, 553-566.

28. AIMAll (Version 13.05.06), Todd A. Keith, TK Gristmill Software, Overland Park KS, USA, 2013.

29. GaussView, Version 5.0.8, R. Dennington, T. A. Keith, J. M. Millam, Semichem Inc., Shawnee Mission, KS, 2016. 


\section{Graphycal Abstract}

Hydrogen- and halogen-bond cooperativity in determining the crystal packing of dihalogen Charge-Transfer adducts: a study case from heterocyclic pentatomic chalcogenone donors

R. Montis ${ }^{*}$ M. Arca, ${ }^{a}$ M.C. Aragoni, A. Bauzá, F. Demartin, A. Frontera, ${ }^{*}$ F. Isaia, V. Lippolis ${ }^{*}$

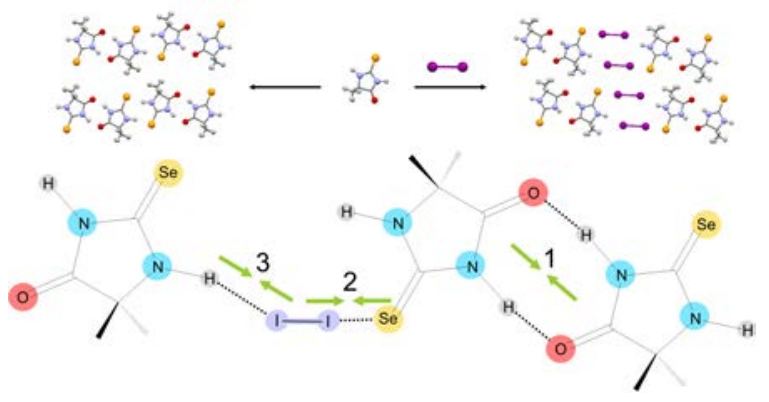

A favorable synergic cooperation between $\mathrm{HB}$ and $\mathrm{XB}$ interactions is at the base of the supramolecular architectures in dihalogen CT adducts of hydantoin-like chalcogen donors. 